\title{
Transient Convective Heat Transfer
}

\author{
J. Padet \\ UTAP - Laboratoire de Thermomécanique, \\ Faculté des Sciences \\ B.P. 1039, 51687 REIMS, France \\ jacques.padet@univ-reims.fr
}

In nature, as well as within the human-made thermal systems, the time-variable regimes are more commonly encountered, if not always, than the permanent regimes. Nevertheless, studies in convection are still more frequent in the permanent regimes, undoubtedly due to the related difficulties in calculation in terms of time and cost of computation.

One may distinguish two categories of time-dependent transfers: those which are due to external causes (variable boundary conditions) and those that are due to internal causes (sources of variable power, instabilities, turbulence), and the combination of these two types may also be encountered.

In this presentation, we shall analyze some situations which belong to the first category. These are concerned with:

- a group of boundary layer flows in forced, natural or mixed convection, where the wall is subjected to time-variable conditions in temperature or flux.

- another group of fluid flows within ducts, in laminar mixed convection regime, where the entry conditions (mass flow rate, temperature) are time-dependent.

The techniques of analysis are mainly extensions to the differential method and to the integral method of Karman-Polhausen in boundary layer flows, and the finite differences solution of the vorticity and energy equations for internal flows.

The results presented in the transient state are caused by steps of temperature, heat flux or velocity, and in particular show the time evolution of the dynamic and thermal boundary layers, as well of the heat transfer coefficients.

Three examples of applications will then be treated: the active control of convective transfers, the measurement of heat transfer coefficients, and the analysis of heat exchangers.

The main idea in the active control is that of managing the temperatures or heat fluxes by employing a variable regime. Under certain conditions, this procedure may reveal itself quite interesting.

The measurement of transfer coefficients by the photothermal impulse method possesses a great interest since it is performed in a non-intrusive way without contact. However, in order to be precise, it needs to account for the thermal boundary layer perturbation due to the radiative flux sent over the surface, which means to know the evolution of the transfer coefficient during the measurement. Previous studies therefore provide essential information.

Within the domain of heat exchangers, we shall present a different global method, which allows for the evaluation of the time constant of an equipment in response to sample variations of temperature or mass flow rates at the entrance.

In conclusion, a brief balance of the ICHMT Symposium "Transient heat and mass transfer", Cesme, Turkey, August 2003, will be presented.

Keywords: Transient, heat transfer.

\section{Introduction}

Transient convection is of fundamental interest in many industrial and environmental situations such as air conditioning systems, human comfort in buildings, atmospheric flows, motors, thermal regulation process, cooling of electronic devices, security of energy systems... Many works reported in literature deal with stationary velocity and temperature fields, but only a small number deal with time - variable boundary conditions [1, 2, 3, 4], either in forced, natural or mixed convection.

In this lecture, we intend to complete previous analysis and to introduce researches about transient convection realised at the UTAP-LTM laboratory in Reims.

\section{Forced Convection}

\section{Description of the Problem}

The aim of this first part is to present a detailed numerical study of the transient forced laminar convective heat transfer over a flat

\footnotetext{
Presented at ENCIT2004 - 10th Brazilian Congress of Thermal Sciences and Engineering, Nov. 29 -- Dec. 03, 2004, Rio de Janeiro, RJ, Brazil. Technical Editor: Atila P. Silva Freire.
}

plate or a wedge, when the thermal field is due to different kinds of variations - in time and space - of some boundary conditions, i.e. wall temperature or wall heat flux. The governing equations are solved using extensions either of the differential method, or the Karman - Pohlhausen integral approach. Let precise that in this whole part, we consider uncoupled situations, i.e. the velocity field does not depend on the thermal field.

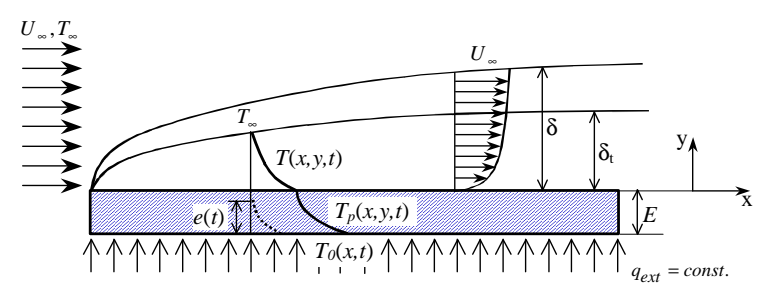

Figure 2.1. Representation of the physical model.

\section{Plate with No Thickness}

The considered case is a flat plate (or a wedge) with no thickness subjected to a change in either the wall temperature or the wall heat flux (fig.2.1, 2.2). 


\section{Differential Method [5] [6] [7]}

First introduce as an example transient laminar forced convection from a wedge subjected to a positive step change in its surface temperature. At time $t<0$, a flow is deflected through an angle $\beta \pi / 2$ between the $\mathrm{x}$-direction on the wedge surface and the direction of flow. The coefficient $\beta$ is defined as: $\beta=2 m /(m+1)$, where $m$ is the pressure-gradient parameter along the $\mathrm{x}$-direction, so that $U_{\infty}(x)=C x^{m}$, where $C$ is a constant. Of course, the special case $m=0$ describes the flow on a flat plate without pressure gradient. Initially, the flow and the surface wedge are both at the same temperature, $T_{\infty}$. At time $t=0$, the surface temperature of the wedge is changed to the value $T_{p}$ and subsequently held constant, therefore setting up a time-dependent thermal boundary layer.

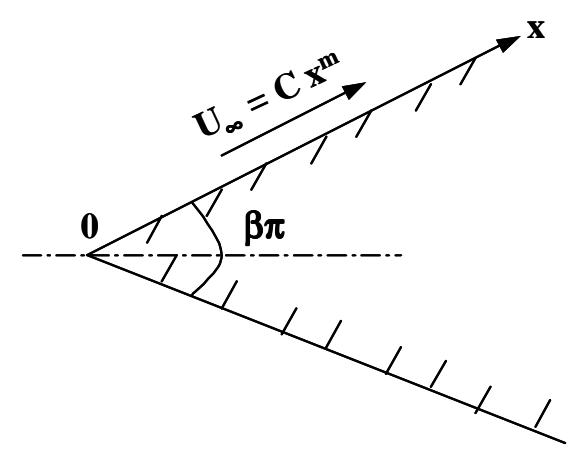

Figure 2.2. Flow over a wedge.

The partial differential equations that describe the problem are:

$$
\begin{gathered}
\frac{\partial U}{\partial x}+\frac{\partial V}{\partial y}=0 \\
U \frac{\partial U}{\partial x}+V \frac{\partial U}{\partial y}=-\frac{1}{\rho} \frac{d p}{d x}+v \frac{\partial^{2} U}{\partial y^{2}} \\
\frac{\partial T}{\partial t}+U \frac{\partial T}{\partial x}+V \frac{\partial T}{\partial y}=a \frac{\partial^{2} T}{\partial y^{2}}
\end{gathered}
$$

The boundary conditions are as follows:

at the surface: $U(x, 0)=V(x, 0)=0$

in the free stream : $U(x, \infty)=U_{\infty}(x)$ and $T(x, \infty, t)=T_{\infty}$

and the initial conditions:

$$
t=0: \quad T(x, y, t)=T_{\infty} \quad ; \quad t \geq 0: \quad T(x, 0, t)=T_{p}
$$

Defining the dimensionless quantities:

$$
\eta=\frac{y}{\sqrt{v x / U_{\infty}}}, t^{+}=\frac{U_{\infty}}{x} t, \text { and } T^{*}=T^{*}\left(\eta, t^{+}\right)=\frac{T-T_{\infty}}{T_{p}-T_{\infty}}
$$

the velocity components in $\mathrm{x}$ and $\mathrm{y}$ directions are expressed as follows:

$$
U=U_{\infty} F^{\prime}(\eta) \quad V=\frac{1}{2} \sqrt{\frac{U_{\infty} v}{x}}\left(\eta F^{\prime}-(m+1) F\right)
$$

where 'prime' denotes the differentiation with respect to $\eta$.
By introduction of the transformation variables in the momentum equation, the dimensionless stream function, $F(\eta)$, verifies the known Falkner-Skan equation:

$$
F^{\prime \prime \prime}+\frac{m+1}{2} F F^{\prime}+m\left(1-F^{\prime 2}\right)=0
$$

For a sudden change in the wedge temperature, we show that the dimensionless quantities $\eta, t^{+}$and $T^{*}$ verifie the differential equation:

$$
\frac{1}{P r} T^{* \prime \prime}+\frac{m+1}{2} F T^{* \prime}=\left[1+(m-1) F^{\prime} t^{+}\right]\left(\frac{\partial T^{*}}{\partial t^{+}}\right)
$$

with the boundary and initial conditions:

$$
\begin{gathered}
F^{\prime}(\eta=0)=0 ; \quad F^{\prime}(\eta=\infty)=1 \\
t^{+}=0 ; \quad T^{*}\left(\eta, t^{+}\right)=0 \\
t^{+} \geq 0 ; \quad T^{*}\left(0, t^{+}\right)=1 \quad \text { and } \quad T^{*}\left(\infty, t^{+}\right)=0
\end{gathered}
$$

The gradient-pressure parameter $\mathrm{m}$ can be positive or negative; negative values are encountered, for example, near the rear of a wedge. For attached boundary layers, the solutions of equation (7) are limited to values of $m$ in the range $-0.09 \leq m \leq \infty$.

\section{Integral Method [8]}

The use of the KP integral approach to solve unsteady thermophysical problems ineluctably leads to the questioning about the thermal boundary layer thickness behaviour (see $\S$ 2.2.4.2); indeed, this approach is based on the integration of the momentum and energy equations within the own boundary layers thickness.

Under the usual boundary layer hypotheses, the integral equation of the temperature distribution $\Theta$ within the thermal boundary layer thickness is given by

$$
\frac{\partial}{\partial t} \int_{0}^{\delta_{T}(x)} \Theta d y+\frac{\partial}{\partial x} \int_{0}^{\delta_{T}(x)} \Theta U d y=-\frac{v}{P r}\left(\frac{\partial \Theta}{\partial y}\right)_{y=0}
$$

where $\mathrm{U}$ is the streamwise velocity component and $v$, Pr respectively the kinematic viscosity and Prandtl number of the fluid. It will be recalled that the formulation (5) is only suitable in the range $\operatorname{Pr} \geq 0.5$ [7].

Using the $4^{\text {th }}$ order Pohlhausen method, the velocity and temperature profiles are given by:

$$
U=U_{\infty}\left(2 \frac{y}{\delta}-2 \frac{y^{3}}{\delta^{3}}+\frac{y^{4}}{\delta^{4}}\right) ; \quad \Theta=\Theta_{p}\left(1-2 \frac{y}{\delta_{T}}+2 \frac{y^{3}}{\delta_{T}^{3}}-\frac{y^{4}}{\delta_{T}^{4}}\right)
$$

where $\Theta_{p}$ is the surface temperature.

We will chose here as example a condition of uniform flux steps: at time $\mathrm{t}=0$, the wall heat flux density changes suddenly from $\Phi_{0}$ to $\Phi_{1}$. Substitutions and application of the Fourier law $(\partial \Theta /$ $\partial \mathrm{y})_{\mathrm{y}=0}=-\left(\Phi_{1} / \lambda_{\mathrm{f}}\right)$ gives the final equation for either heating or partial cooling problems, where $\Delta=\delta_{\mathrm{T}} / \delta$ and $\zeta$ is a constant characterising the dynamical boundary layer $(\zeta \approx 5,83)$ : 


$$
\frac{3}{10} x \Delta \frac{\partial \Theta_{p}}{\partial t}+\frac{2 U_{\infty}}{\Delta \zeta^{2} \operatorname{Pr}}\left[x \frac{\partial \Theta_{p}}{\partial x}+\frac{\Theta_{p}}{2}\right]=\frac{\Phi_{1} v \sqrt{R e_{x}}}{\zeta \lambda_{f} \operatorname{Pr}}
$$

It will be noticed this equation is not suitable for unsteady fully cooling problems, in which $\Phi_{1}=0$; in such cases, the condition of a zero surface temperature gradient leads to another temperature polynomial profile.

The initial and boundary conditions on the temperature are given by the classical theory:

$$
\Theta_{p}(x, 0)=\frac{\Phi_{0} \Delta \zeta}{2 \lambda_{f}} \frac{x}{\sqrt{R e_{x}}} ; \quad \Theta_{p}(0, t)=0
$$

\section{Comparison in Steady State [9] [10]}

Two reasons have justified to check the semi-analytical solutions in steady state. The first one is that appears in the literature, on the one hand a lack of data in the whole range of fluid Prandtl numbers, and on the other hand that some published data seem to be wrong. The second reason is that the perfect knowledge of steady state solutions is of very important interest in treating transient convective problems because they are no more than asymptotical solutions of unsteady problems, i.e. the initial solutions for cooling problems and the final solutions for heating ones.

The results have been plotted on fig. 2.3 and 2.4, in addition to the corresponding correlations with their Pr limit values. They show a good concordance between the two methods.

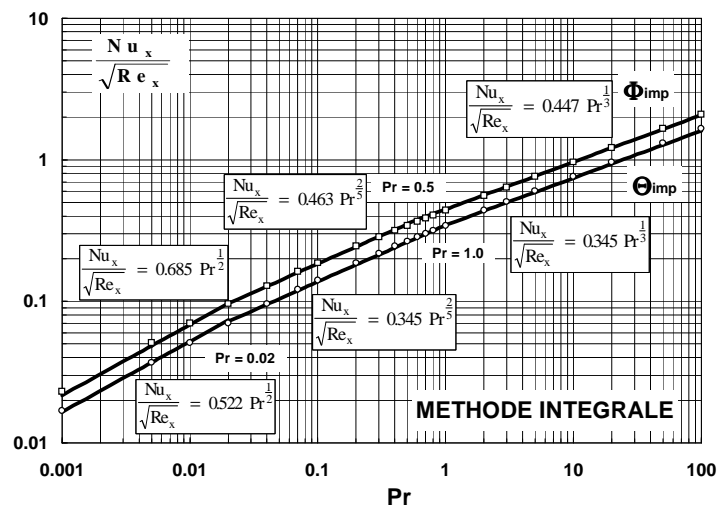

Figure 2.3. Evolution laws of Nux / (Rex)1/2 versus Pr deduced from INTEGRAL method.

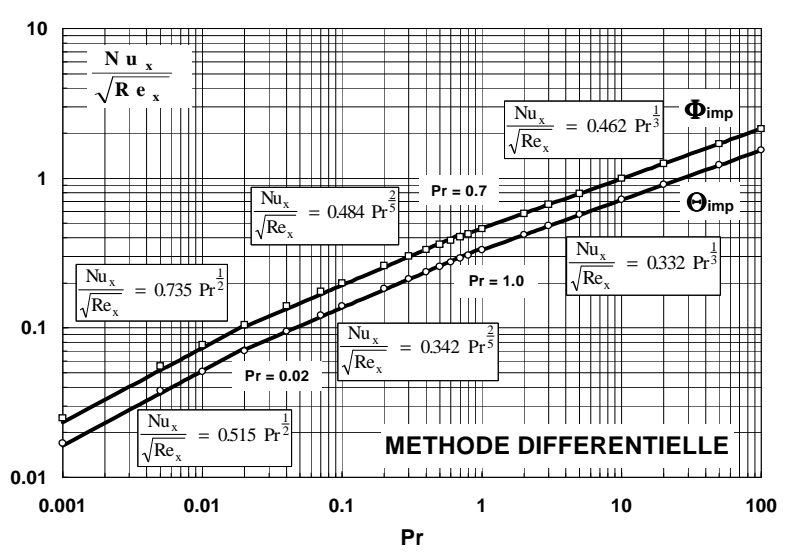

Figure 2.4. Evolution laws of $\mathrm{Nux} /(\operatorname{Rex}) 1 / 2$ versus $\mathrm{Pr}$ deduced from DIFFERENTIAL method.
It was also shown that in the integral method, 2 or 3 -order polynomials should be avoided, because the unicity of the solution is obtained only with the 4-order.

Other comparisons were made under transient conditions. They show some tiny differences between the two methods in the external part of the boundary layers, but the results are very similar near the wall.

\section{Results}

Now, let us come back to transient states.

\section{Temperature Steps [11]}

Consider first a semi-infinite plate with constant and uniform temperature $T_{p 1}$. Far from the plate, the velocity $U_{\infty}$ and temperature $\mathrm{T}_{\infty}$ remain constant. At time $\mathrm{t}=0$, the plate temperature is suddenly changed to $\mathrm{T}_{\mathrm{p} 2}\left(\mathrm{~T}_{\mathrm{p} 2}<\mathrm{T}_{\mathrm{p} 1}\right.$ or $\left.\mathrm{T}_{\mathrm{p} 2}>\mathrm{T}_{\mathrm{p} 1}\right)$.

Results plotted on fig. 2.6 and 2.7 have been obtained from the differential method (\$.2.2.1) and for a water flow $(\operatorname{Pr}=7)$. The parameter $\mathrm{R}_{\mathrm{t}}$ means $\mathrm{T}^{*}{ }_{\mathrm{p} 1} / \mathrm{T}^{*}{ }_{\mathrm{p} 2}$. In these two cases, the steady state is reached at a dimensionless time $\mathrm{t}^{+}$close to 4,36 (see also $§ 2.2 .4 .6$ for transient state duration). Fig.2.8 shows the evolution of the instantaneous dimensionless coefficient $\mathrm{h}^{+}$in the same thermal conditions and for several values of Pr. It can be seen that highest $\mathrm{Pr}$ correspond to longest time durations.

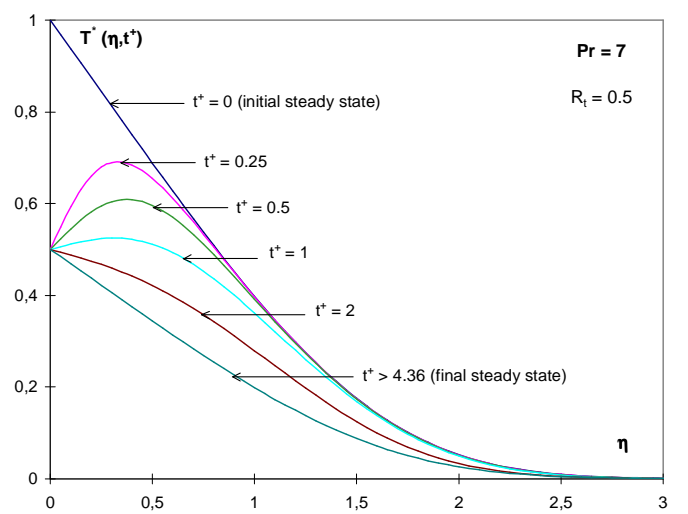

Figure 2.6. Transient temperature profiles for a negative step change in the plate temperature.

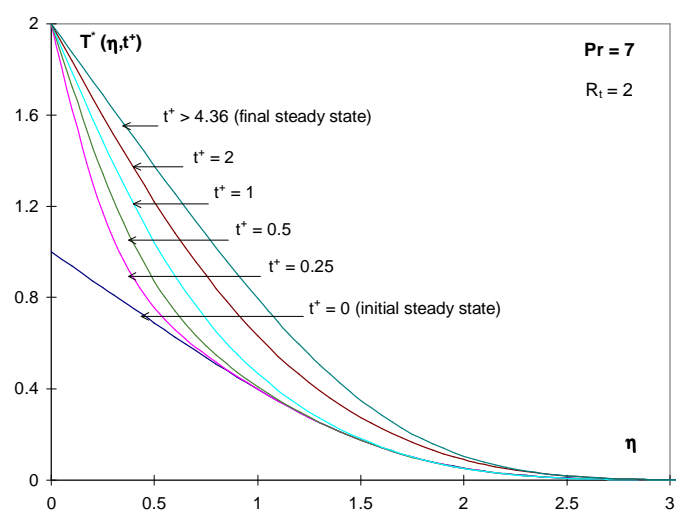

Figure 2.7. Transient temperature profiles for a positive step change in the plate temperature. 

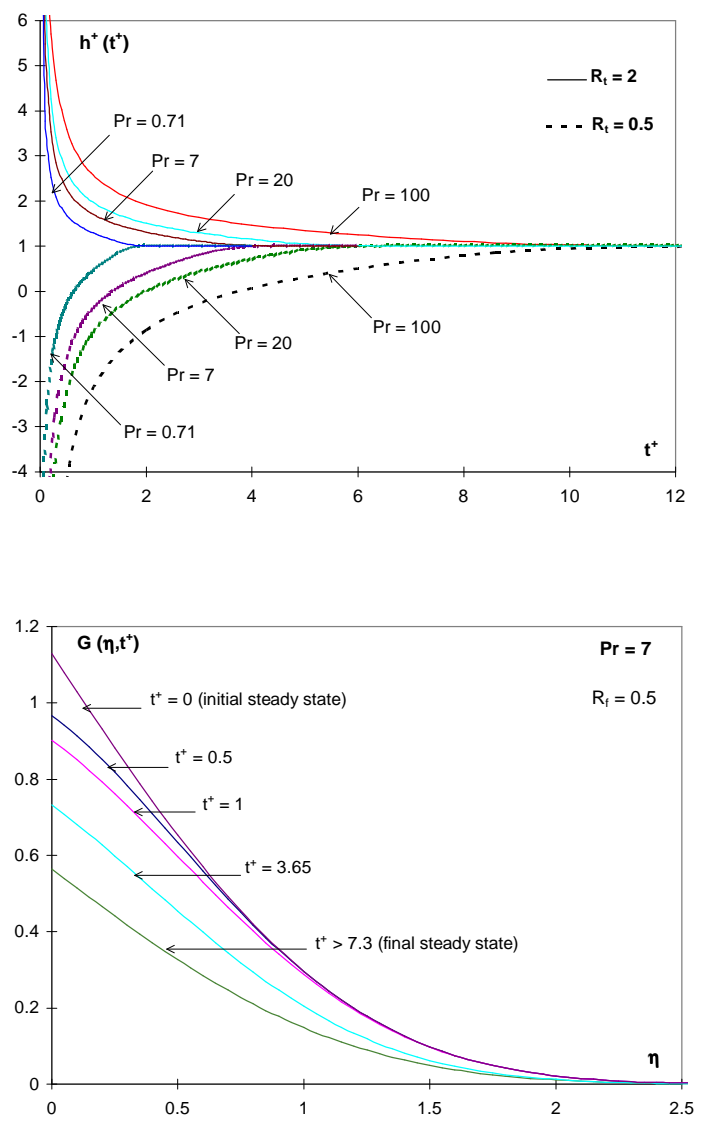

Figure 2.9. Transient temperature profiles for a negative step change in the plate heat flux.

\section{Uniform Heat Flux Steps}

a)- Step from a zero state, followed by relaxation [8]

In order to discuss the behaviour of the boundary layer thickness in the general case, it is necessary to make a short description of the heating process from an isothermal state. In that case, we can attend the birth of a thermal boundary layer, which thickness $\delta_{\mathrm{T}}$ grows from zero to its stationary value (an illustration is given $\S 2.2 .4 .3$, fig. 2.13).

Now, from the stationary state, heating is cut suddenly: the thermal boundary layer changes in a very different way: it does not collapse, it uniformly vanishes, without any variation in its thickness.

b)- Change from a heating steady state to another one [8] [11] [12] [13]

Consider now heating or cooling phases from a first heating steady state. We know that, in steady state, $\delta_{\mathrm{T}}$ does not depend on the wall heat flux. So we are allowed to assume that $\delta_{\mathrm{T}}$ remains constant during a heating phase. Indeed, this assumption has no interest with the differential method, but is very essential and useful in the Karman - Pohlhausen method, in which $\delta_{\mathrm{T}}$ is a fundamental parameter.

Some results are presented below. The curves plotted on fig. 2.9 and 2.10 were obtained from the differential method. The parameter $\mathrm{G}$ is the dimensionless temperature corresponding to an imposed wall heat flux $\Phi$, and $\mathrm{R}_{\mathrm{f}}=\Phi_{\text {final }} / \Phi_{\text {initial }}$. They show that the thermal boundary layer thickness does not change during the transient state, and that the duration of this transient is longer than in the case of a temperature step $\left(\mathrm{t}^{+}\right.$around 7.3 instead of 4.36, $\S 2.2 .4 .1$; see also $\S$ 2.2.4.6).

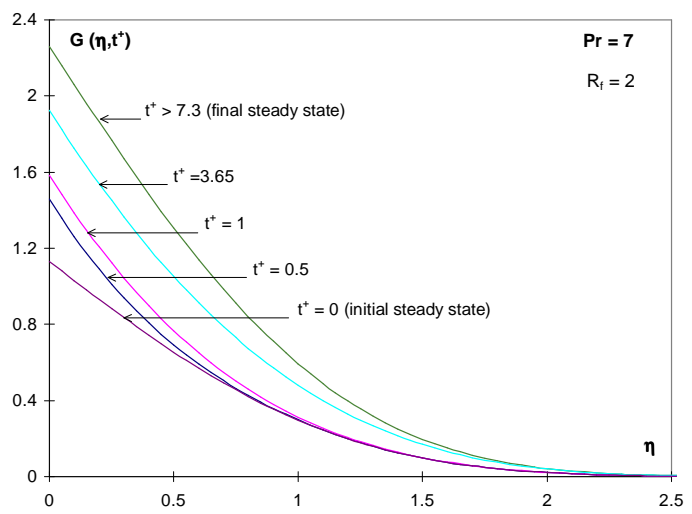

Figure 2.10. Transient temperature profiles for a positive step change in the plate heat flux.

Figures 2.11 and 2.12 show results obtained from the integral method, with an air flow. Two step changes arise at times $t=0$ and $\mathrm{t}=0.3 \mathrm{~s}$. It can be observed that the wall temperatures at different abcissas $\mathrm{x}$ admit a common envelope corresponding to the final steady state, and that the response is slower as $\mathrm{x}$ increases.

As for instantaneous Nusselt numbers, they decrease from infinity after each step.

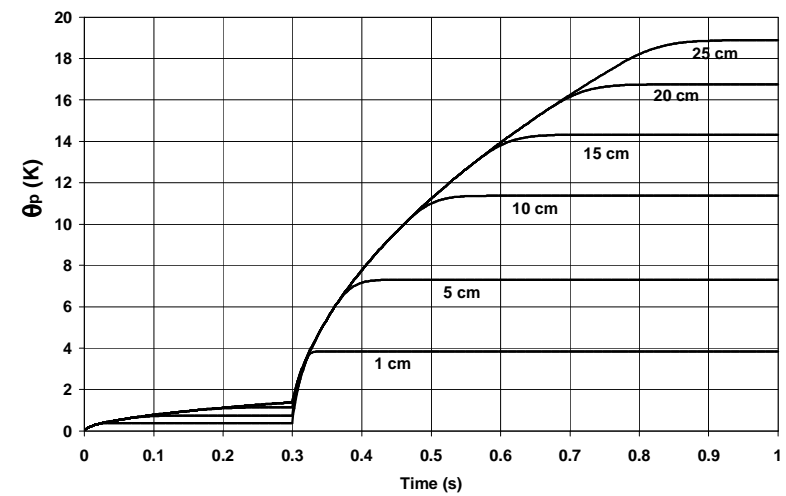

Figure 2.11. Wall temperatures in the case of heat flux steps, from 10 to $100 \mathrm{~W} / \mathrm{m}^{2}$.

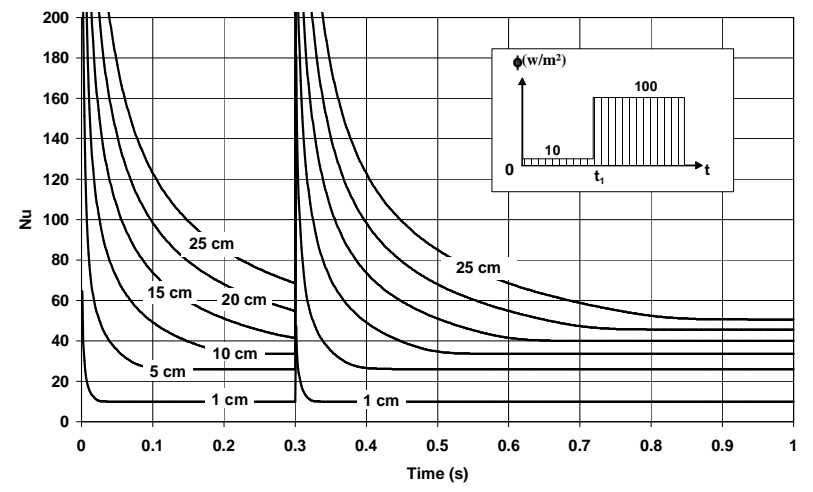

Figure 2.12. Transient Nusselt number at different locations $\mathbf{x}$ (heat flux steps). 


\section{Spatially Varying Heat Flux Steps [14] [15]}

An extension of the KP model has been performed, in which arbitrary flux densities are applied along the wall.
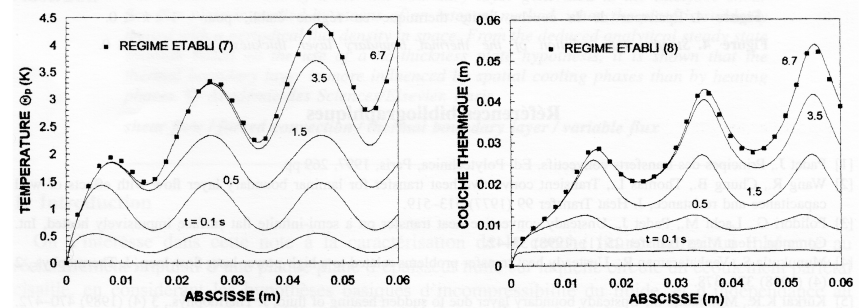

Figure 2.13. Sinusoidal wall heat flux $\varphi(x)$ step (from $\varphi=0$ ).

First, fig. 2.13 shows the thermal response to a heat flux step, when the spatial distribution of $\varphi(x)$ is sinusoidal. The diagram right is of special interest, as it shows the creation of a boundary layer, and the variation in time of its thickness, from zero to the steady state value $(\$ 2.2 .4 .2, \mathrm{a})$

The following figures correspond to step changes from / to three different spatial heat flux distributions, denoted as $\varphi_{1}, \varphi_{2}, \varphi_{3}$ (fig. 2.14 ), including a heating process from uniform temperature, and a sudden change from cooling to heating (fig. 2.19). Specially, pay attention to fig. 2.21, corresponding to this last case. It shows a kind of propagation wave of the heat transfer coefficient, and the displacement of the point where the wall temperature equals zero, corresponding to $h=\infty$.

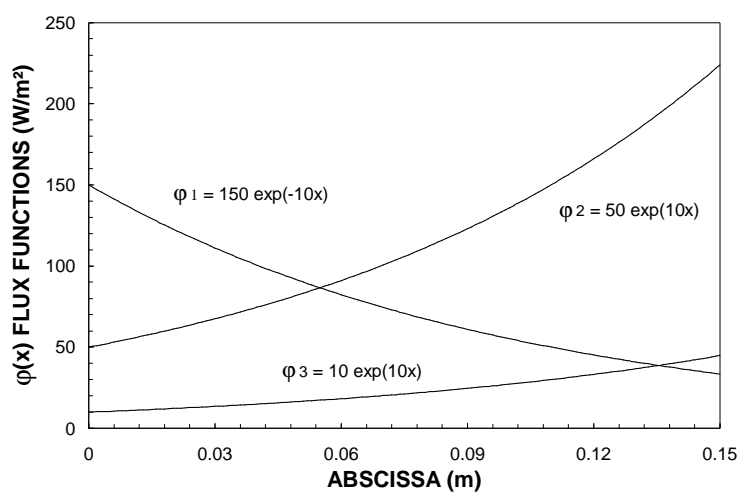

Figure 2.14. Choice of arbitrary flux densities.

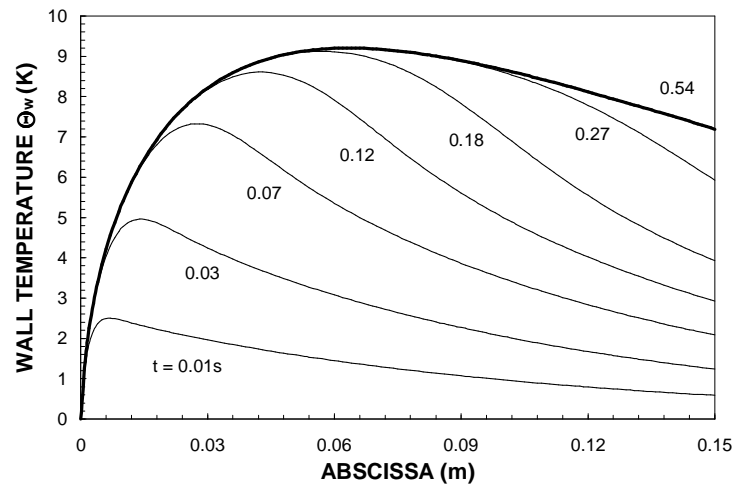

Figure 2.15. Unsteady wall temperature in heating process $[0 \rightarrow \varphi 1(x)]$.

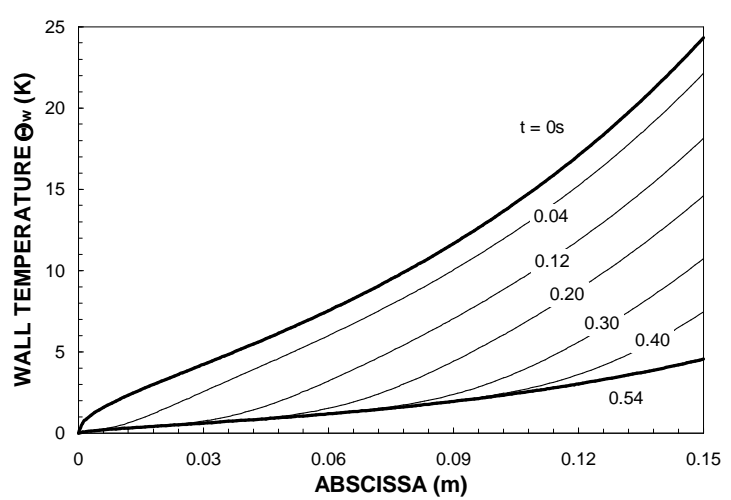

Figure 2.16. Wall temperature evolution in the case $[\varphi 2(x) \rightarrow \varphi 3(x)]$.

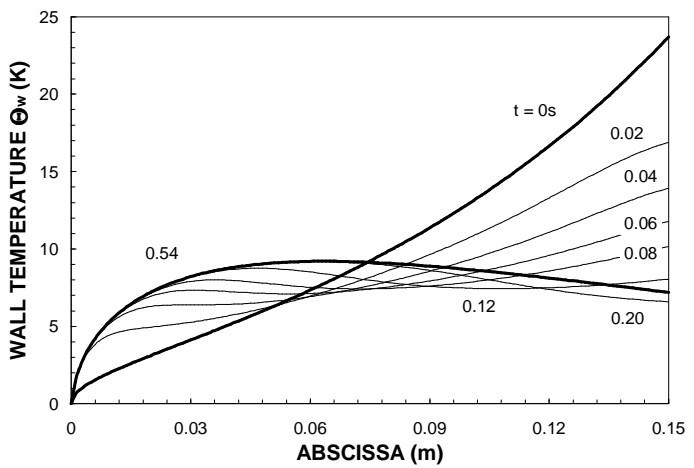

Figure 2.17. Wall temperature evolution in the case $[\varphi 2(x) \rightarrow \varphi 1(x)]$

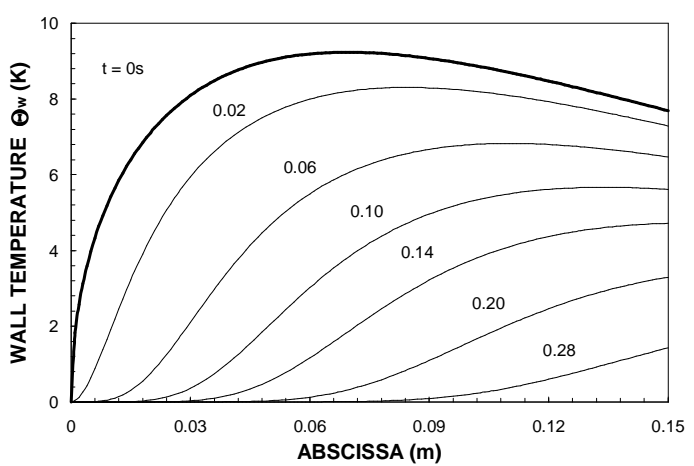

Figure 2.18. Wall temperature evolution in fully cooling phase $[\varphi 1(x) \stackrel{\sim}{\rightarrow}]$.

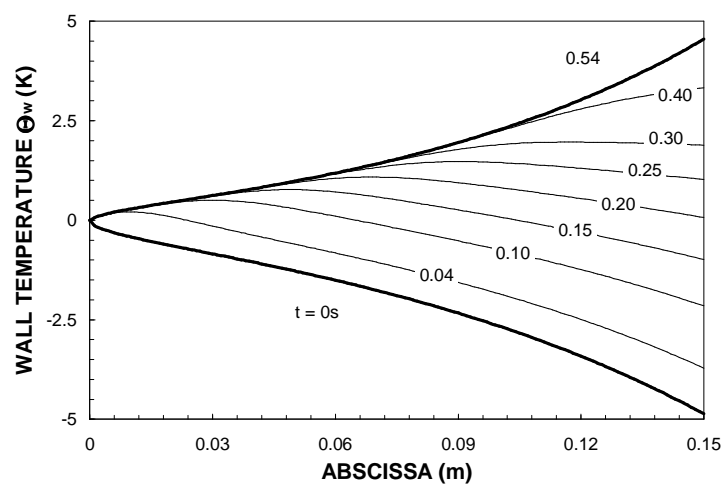

Figure 2.19. Wall temperature evolution in the case $[-\varphi 3(x) \rightarrow \varphi 3(x)]$ 


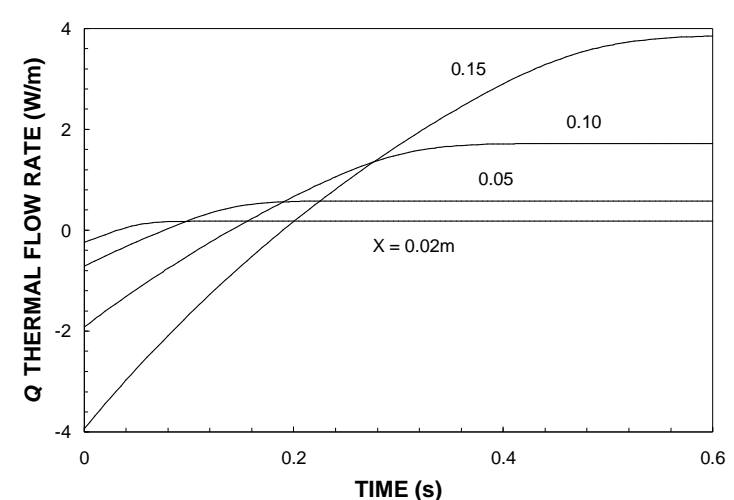

Figure 2.20. Thermal flow rate as a function of time for different abscissa (case $[-\varphi 3 \rightarrow \varphi 3]$ ).

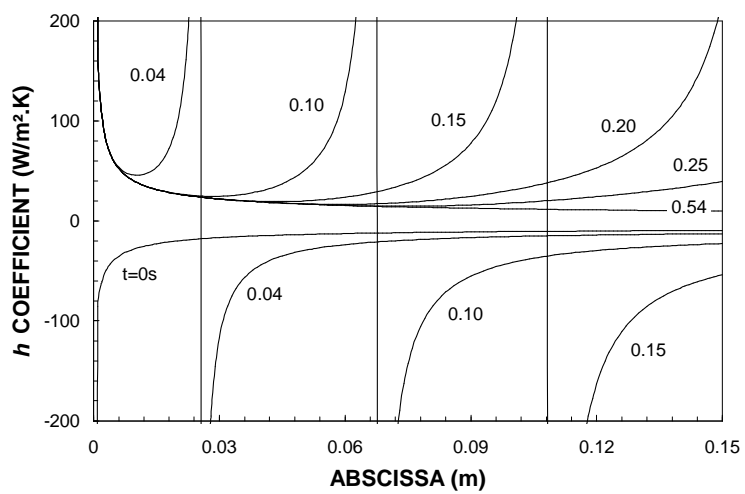

Figure 2.21. Heat transfer coefficient for different times (case [- (3((3]).

\section{Uniform Periodic Heat Flux [16]}

A situation of practical interest consists in periodic boundary conditions, uniform periodic heat flux as example. A comparison between three different signal shapes (in time) is reported on fig. 2.22. As it can be seen, successive sinusoidal signals give a higher average wall temperature than triangular ones.

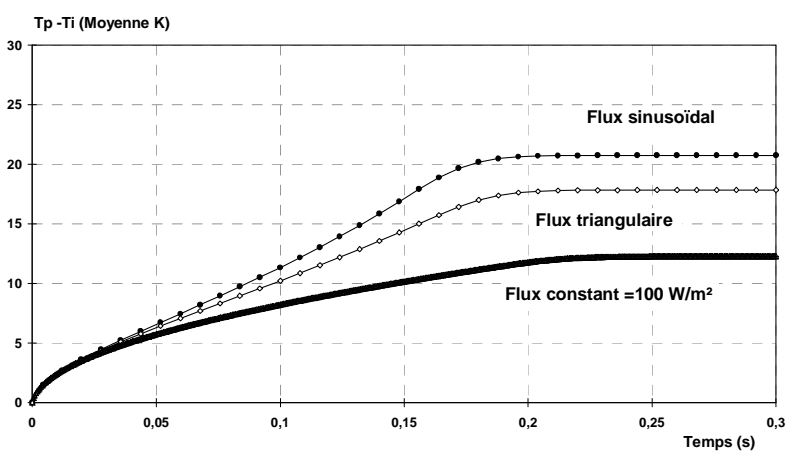

Figure 2.22. Average temperatures corresponding to different shapes of periodic flux Air flow. Period T $=0.008 \mathrm{~s}$.

\section{Dimensioned and Dimensionless Results [12] [13] [17] [20]}

Regarding experimental or numerical results in convective heat transfer, a very important issue consists in the best way to express them: by the mean of dimensioned or dimensionless data? Of course, dimensionless numbers seem to be more convenient, as they combine several physical parameters. But they can drive to wrong interpretations, because the appearances that we are able to see in the results can be very different according as they are dimensioned or not. Moreover, in a practical way, engineers are interested only by dimensioned data. Two examples are given below (see also $\S$ 2.2.4.2).

In the first case, heat flux density suddenly decreases. The Nusselt number and the heat transfer coefficient $h$ (in an air flow) are plotted versus time: it can be easily observed that their trends appear very different (fig. 2.23, 2.24).

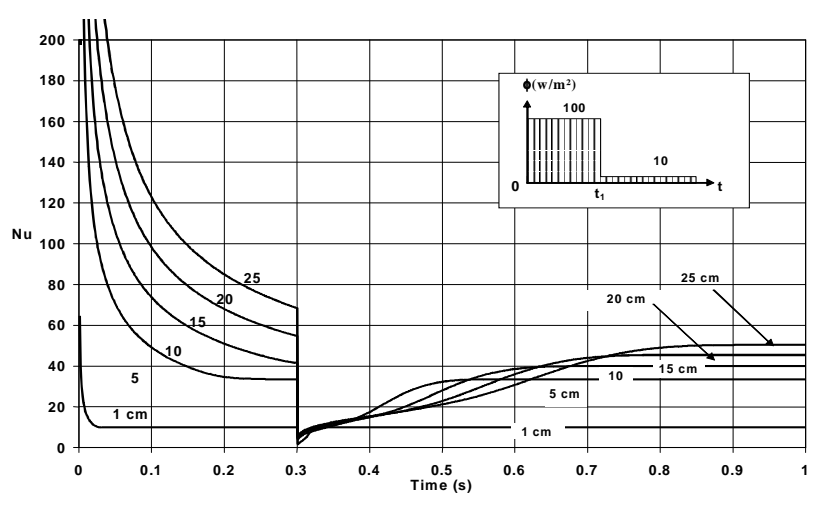

Figure 2.23. Sudden cooling: Nusselt number as a function of dimensionless time.

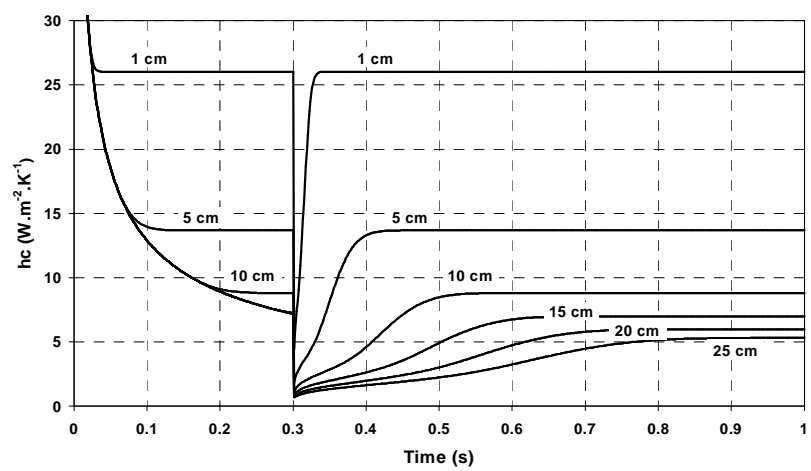

Figure 2.24 . Sudden cooling: heat transfer coefficient, at different locations $\mathbf{x}$.

In the second case (fig. $2.25,2.26$ ) a temperature step is imposed on the wall, in a water flow $\left(\mathrm{U}_{\infty}=0.5 \mathrm{~m} / \mathrm{s}\right)$. A unique curve describes the evolution of the dimensionless wall heat flux ( $\left.T^{*}\right)^{\prime}$ as a function of dimensionless time $t^{+}$, but $h$ versus dimensioned $t$ does not obey to the same rule, and crossings in the curves appear, that cannot be guessed from the dimensionless plotting.

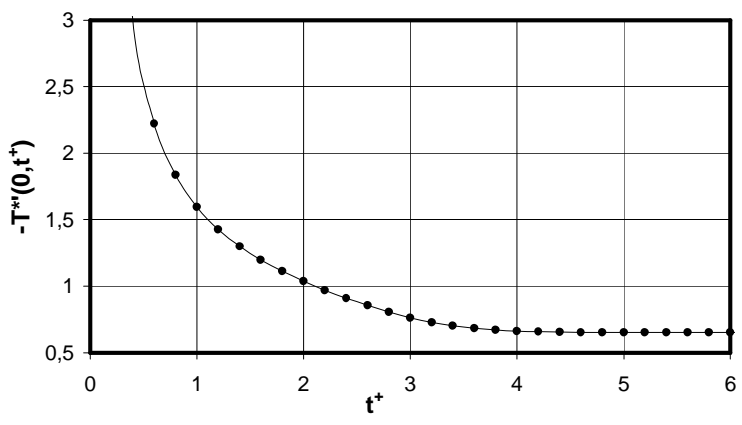

Figure 2.25. Wall dimensionless heat flux for Blasius flow $(m=0)$. 


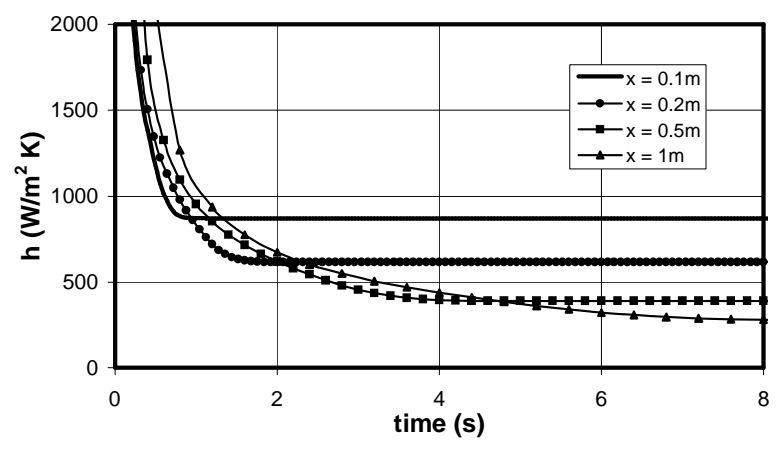

Figure 2.26. Instantaneous convective heat transfer coefficient at different abscissa.

\section{Transient State Duration [5] [12] [18] [19]}

Another fundamental and practical problem consists in characterising the "response speed" of a system. This can be done in several ways, for example:

1- Time constant $\tau$ deduced from an exponential fitting of the temperature response, as shown below (fig. 2.27) in a Blasius air flow $\left(\mathrm{U}_{\infty}=1 \mathrm{~m} / \mathrm{s}\right)$, with a heat flux step [18].

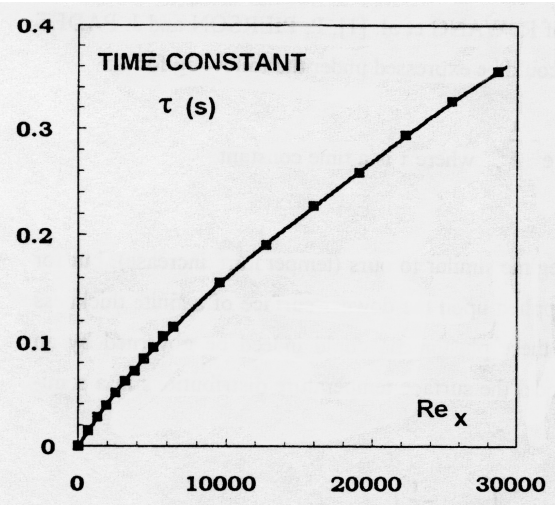

Figure 2.27. Time constant in seconds (air flow, velocity = $1 \mathrm{~m} / \mathrm{s}$ ).

2- Transient duration defined as the time when the difference between instantaneous and steady state heat transfer coefficients become less than $1 \%$ [19] [12].

An example is given on Table 1 for a wall temperature step on a wedge or in a velocity gradient flow (§ 2.2.1). It shows that the transient duration $\mathrm{d}$ (expressed in seconds) for the wall heat flux increases with $\mathrm{x}$, except near $\mathrm{m}=1$ where it becomes independent of x. Obviously, it increases also with Pr.

Once more, this offers the opportunity to pay attention to dimensioned compared to dimensionless presentation of numerical results. Dimensionless results show a transient duration increasing as $m$ decreases [5]. On the contrary, it appears on Table 1 that the real (dimensioned) duration has a minimum for $\mathrm{m}$ close to zero.

Complementary data about transient durations can be found in $\S$ 2.2.4.1.

Table 1. Flow over a wedge: dimensioned transient duration $\mathrm{d}$ (in seconds).

\begin{tabular}{|c|c|c|c|c|c|c|c|c|}
\hline Pr & $\mathbf{m}$ & $\beta \pi / 2$ & $\begin{array}{c}\mathrm{U}_{\infty}(\mathrm{m} / \mathrm{s}) \text { in } \\
\mathrm{x}_{1}=0.166 \mathrm{~m}\end{array}$ & $d(s)$ in $x_{1}$ & $\begin{array}{l}\mathrm{U}_{\infty}(\mathrm{m} / \mathrm{s}) \mathrm{in} \\
\mathrm{x}_{2}=0.5 \mathrm{~m}\end{array}$ & $d(s)$ in $x_{2}$ & $\begin{array}{l}\mathrm{U}_{\infty}(\mathrm{m} / \mathrm{s}) \mathrm{in} \\
\mathrm{x}_{3}=0.8 \mathrm{~m}\end{array}$ & $d(s)$ in $x_{3}$ \\
\hline \multirow[t]{4}{*}{0,71} & $-0,0476$ & $-\pi / 20$ & 0,545 & 0,647 & 0,517 & 2,053 & 0,505 & 3,359 \\
\hline & 0,111 & $\pi / 10$ & 0,410 & 0,663 & 0,463 & 1,766 & 0,488 & 2,682 \\
\hline & 0,333 & $\pi / 4$ & 0,275 & 0,934 & 0,397 & 1,949 & 0,464 & 2,666 \\
\hline & 1 & $\pi / 2$ & 0,083 & 2,917 & 0,250 & 2,917 & 0,400 & 2,917 \\
\hline \multirow{4}{*}{7} & 0 & 0 & 0,500 & 1,304 & 0,500 & 3,929 & 0,500 & 6,286 \\
\hline & 0,111 & $\pi / 10$ & 0,410 & 1,510 & 0,463 & 4,026 & 0,488 & 6,113 \\
\hline & 0,333 & $\pi / 4$ & 0,275 & 2,129 & 0,397 & 4,441 & 0,464 & 6,077 \\
\hline & 1 & $\pi / 2$ & 0,083 & 6,649 & 0,250 & 6,649 & 0,400 & 6,649 \\
\hline \multirow[t]{2}{*}{100} & $-0,0476$ & $-\pi / 20$ & 0,545 & 3,839 & 0,517 & 12,187 & 0,505 & 19,940 \\
\hline & 1 & $\pi / 2$ & 0,083 & 17,319 & 0,250 & 17,319 & 0,400 & 17,319 \\
\hline
\end{tabular}

\section{Finite Thickness Plate}

The case of a finite thickness plate is of better practical interest, but is also more difficult to solve by the mean of half - analytical methods. Indeed, the differential method is inadequate to describe conduction --convection coupled problems. Integral methods can be extended to such situations, but does not seem more suitable than purely numerical methods.

\section{Backward Face: Temperature Step [21] [22]}

An application of an integral approach is given here for an air flow $\left(\mathrm{U}_{\infty}=5 \mathrm{~m} / \mathrm{s}\right)$ along a PVC plate (thickness $\left.\mathrm{E}=1 \mathrm{~cm}\right)$ and a temperature step on the backward face (fig. 2.1). The dimensionless temperature is defined as $\mathrm{T}(\mathrm{t})$ over the steady state temperature. Take notice that its evolution has to be divided in two phases (fig. $2.28)$ : in the first one, the wall is considered as half - infinite; the second one begins when the thermal signal reaches the interface, and needs a polynomial temperature profile different than in the first 
phase, due to the boundary condition on the upward face of the plate.

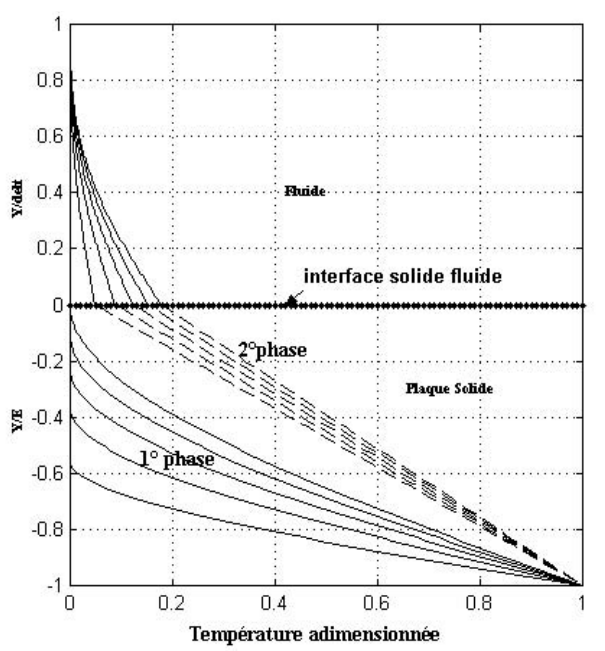

Figure 2.28. Temperature profiles in the PVC wall ( $y / E)$ and in the air $(y / \delta)$, $x=15 \mathrm{~cm}$.

\section{Upward Face: Heat Flux Step [23]}

Consider now a plate isolated on its backward face, and submitted to a heat flux step on the flow side face (upward face): this example corresponds to an experimental set-up used for the measurement of the heat transfer coefficient (§ 5). The same integral method has been recently applied to the determination of the temperature field (fig. 2.29).

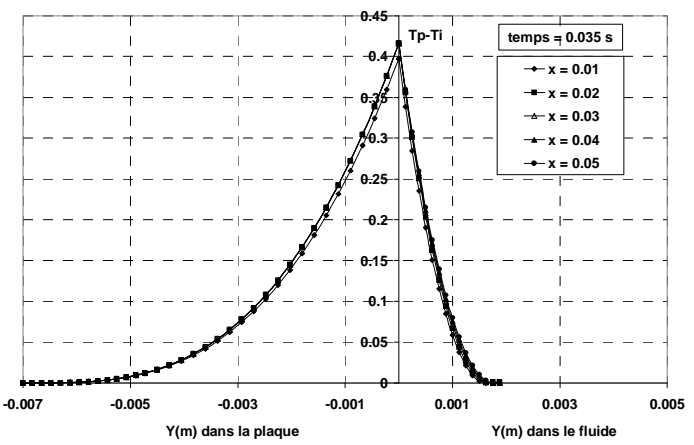

Profils de température pour $\mathrm{t}=0.035 \mathrm{~s}$

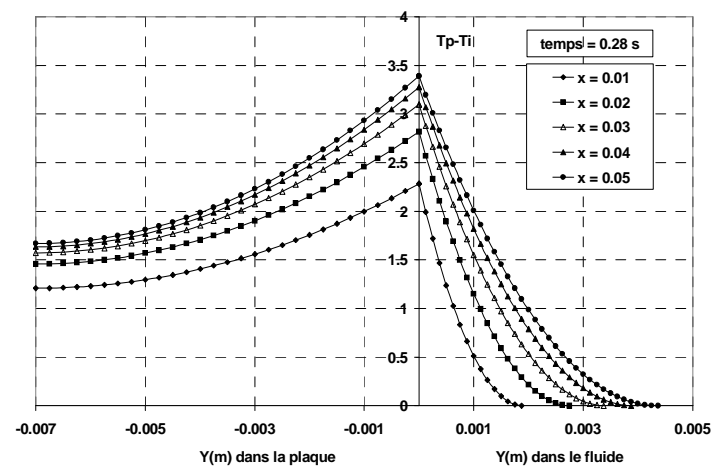

Profils de température pour $\mathrm{t}=0.28 \mathrm{~s}$

Figure 2.29. Heat flux steps on the upward face of the plate temperature profiles in the wall and in the fluid at different times.

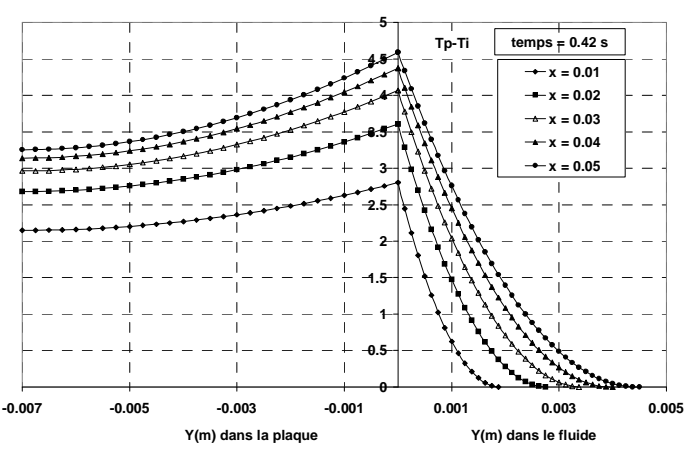

Profils de température pour $\mathrm{t}=0.42 \mathrm{~s}$

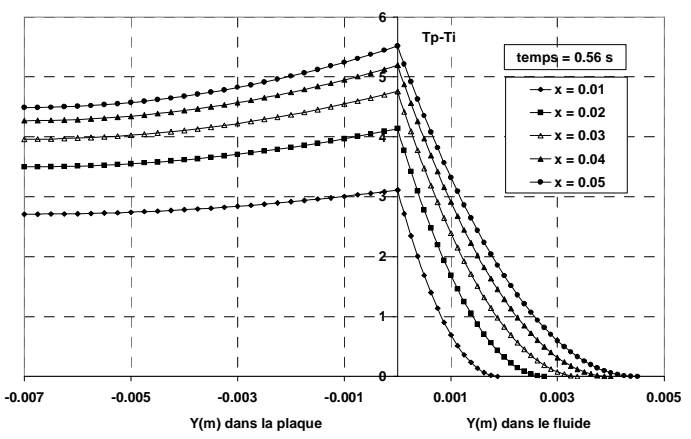

Profils de température pour $\mathrm{t}=0.56 \mathrm{~s}$

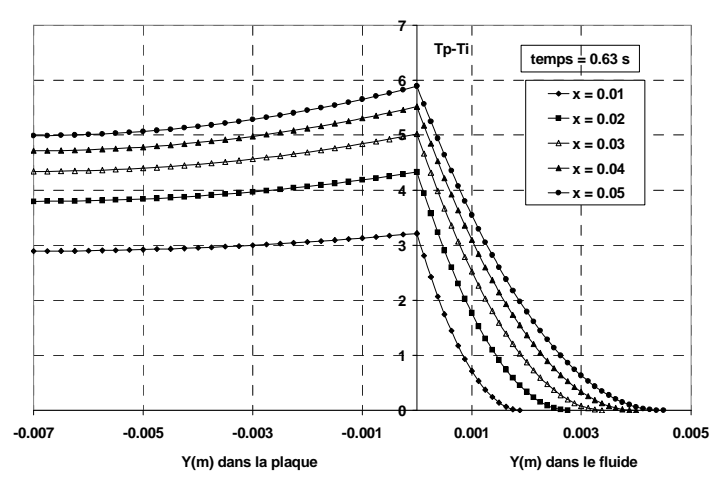

Profils de température pour $\mathrm{t}=0.63 \mathrm{~s}$

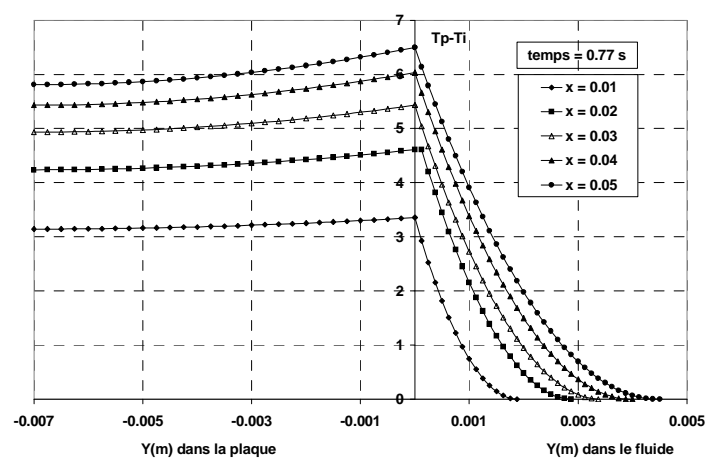

Profils de température pour $\mathrm{t}=0.77 \mathrm{~s}$

Figure 2.29.(Continued).

\section{Impinging Jets}

Regarding laminar impinging jets, let me introduce too a valuable contribution realised by E. Mladin : A 2-D jet impinging over a thick flat plate is submitted to sinusoidal variations of velocity, and a variable heat flux density is imposed on the 
backward face. Numerical solution is obtained by the mean of an integral approach, using 4 - degree polynomials. A panel of results can be found in ref. [24].

\section{Natural Convection}

\section{Introduction}

Among the three types of convective transfers, forced convection is often used because of its efficiency. A contrario, natural convection has the advantage to be free in terms of energy expense but generates low heat transfer coefficient. Thus it will be interesting to improve free convection heat transfer, by the mean of time-dependent boundary conditions.

Laminar free convection problem on a vertical wall has been plentifully investigated considering constant wall heat flux or wall temperature. But it appears in literature that the dynamic behaviour of free convection flows is poorly documented.

Some recent investigations carried out with various timedependent boundary conditions are presented below. They deal with free convection over a vertical plate (fig. 3.1) and were performed by the mean of extended differential or integral methods.

Equations to be solved are the same as in $\S 2.2 .1$ except the momentum equation that becomes:

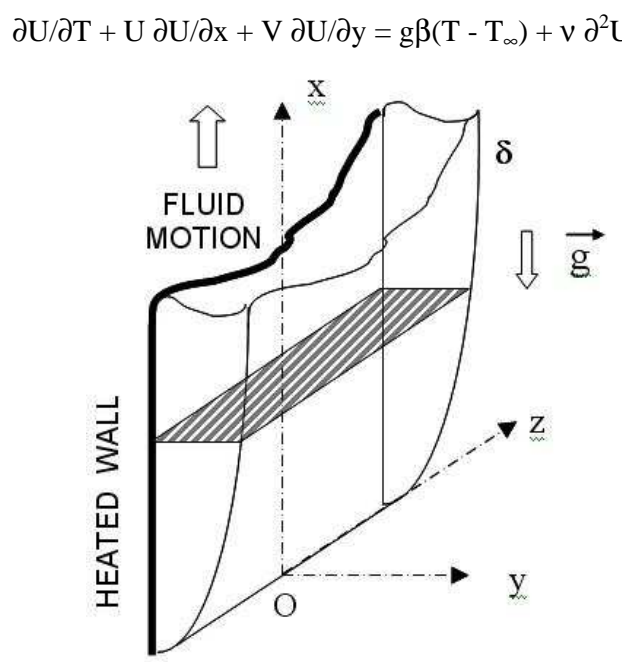

Figure. 3.1. Velocity layer and coordinates system.

\section{Differential Method}

An extension of the method described by Cebeci [2] has been proposed, which involves a generalisation of the differential method, and the use of Keller-box method to solve the equations.

The results are quite similar to those obtained with the integral method, except far from the wall where the differential method gives higher boundary layer thickness [25 to 28].

In the case of periodical wall heat flux, it was found that the thermal boundary layer thickness does not vary and that for low period rates, when the steady state is reached, heat transfer coefficient $\mathrm{h}$ gets its optimal value.

\section{Integral Method}

Using the Karman-Pohlhausen integral method [1, 29], physically polynomial profiles of fourth order are assumed for flow velocity and temperature across the corresponding hydrodynamic and thermal boundary layers. The method of analysis assumes that the velocity and temperature distributions have temporal similarity, meaning that the ratio $\Omega$ between the thermal thickness $\delta_{T}$ and the dynamical thickness $\delta$ depends only upon the Prandtl number during the transient $[30,31,32]$ :

$$
\delta_{T}(x, t)=\Omega(\operatorname{Pr}) \delta(x, t)
$$

Thus, combining this relation with Fourier's law and adequate boundary conditions leads to the following U-velocity and $\Theta$ temperature polynomial distributions depending mainly upon the $\delta$ dynamical parameter [33]:

$$
\begin{gathered}
U=\frac{g \beta \varphi_{w} \Omega \delta^{3}}{12 \lambda v}\left[-\eta^{4}+3 \eta^{3}-3 \eta^{2}+\eta\right] \\
\Theta=T-T_{\infty}=\frac{\varphi_{w} \Omega \delta}{2 \lambda}\left(-\eta_{T}^{4}+2 \eta_{T}^{3}-2 \eta_{T}+1\right)
\end{gathered}
$$

where $\eta=y / \delta \leq 1, \eta_{\mathrm{T}}=\mathrm{y} / \delta_{\mathrm{T}} \leq 1$. Parameters $\beta, \lambda, v, \varphi_{\mathrm{w}}$ are respectively the volumetric coefficient of thermal expansion, the thermal conductivity of the fluid, the kinematic viscosity, and the wall heat flux density.

The integral forms of the boundary-layer momentum and energy conservation equations become then:

$$
\left\{\begin{array}{l}
\frac{\partial}{\partial t} \int_{0}^{\delta} U d y+\frac{\partial}{\partial x} \int_{0}^{\delta} U^{2} d y=g \beta \frac{\partial}{\partial x} \int_{0}^{\Omega \delta} \Theta d y-\left.v \frac{\partial U}{\partial y}\right|_{y=0} \\
\frac{\partial}{\partial t} \int_{0}^{\Omega \delta} \Theta d y+\frac{\partial}{\partial x} \int_{0}^{\Omega \delta} \Theta U d y=-\left.\frac{v}{P r} \frac{\partial \Theta}{\partial y}\right|_{y=0}
\end{array}\right.
$$

The analytical resolution of the system under the assumption $\partial / \partial \mathrm{t}=0$ leads to the knowledge of the boundary layer ratio $\Omega$ and on the other hand gives the steady evolution of the asymptotical $\square$ solution.

Thus, introducing the parameter $\mathrm{K}=\ln (\mathrm{Pr})$, the evolution of the ratio $\Omega(\operatorname{Pr})$ is found to be suitable whatever $\operatorname{Pr}>0.6$ and satisfactorily approached with the following relation :

$$
\Omega=1.57610^{-4} K^{4}-4.22710^{-3} K^{3}+4.28210^{-2} K^{2}-0.1961 K+0.901
$$

The asymptotical limit of the dynamical boundary layer thickness is analytically expressed as:

$$
\delta(x, t \rightarrow \infty)=\left(\frac{432 \lambda v^{2}}{g \beta \varphi_{w} \Omega}(9 \Omega-5) x\right)^{\frac{1}{5}}
$$

Considering the transient regime and using the assumption $\Omega=$ cst, the resolution leads to the combined resulting governing equation of the free convection problem :

$$
\delta \frac{\partial \delta}{\partial t}+\frac{5 g \beta \varphi_{\mathrm{W}}}{72 v \lambda}\left[\frac{\Omega}{12}+\frac{\Omega^{2}}{3}-5 \frac{\Omega^{3}}{14}+9 \frac{\Omega^{4}}{56}-\frac{\Omega^{5}}{36}\right] \delta^{4} \frac{\partial \delta}{\partial x}-\frac{v}{2}\left[9 \Omega-5+\frac{10}{3 \Omega^{2} \operatorname{Pr}}\right]=0
$$

with the following boundary conditions: $\delta(x, t=0)=\delta(x=0, t)=0$.

An explicit finite difference scheme has been used to solve this equation. 


\section{Results}

\section{Eckert's Theory Revisited [30]}

A preliminary issue dealt with the velocity and thermal boundary layers.

First consider that, basically, two different definitions of a boundary layer thickness are commonly used, as for forced, mixed or natural convection:

a)- A standard definition in agreement with the asymptotic structure of a boundary layer: at a distance from the wall equal to the layer thickness, the variation of the considered parameter (velocity, temperature gap) reaches $99 \%$ of its total value.

b)- A mathematical definition linked to the Karman Pohlhausen method: in this theory, the velocity and temperature fields are described by two polynomials, and $\delta$ (or $\delta_{\mathrm{T}}$ ) are the distances from the wall where these polynomials are equal to zero.

Anyway, for a long time, Eckert's theory was accepted. It assumed that, in steady natural convection along a vertical flat plate, $\delta=\delta_{\mathrm{T}}$. This assumption was very useful as it gave a simple way to obtain the $\mathrm{h}$ coefficient, but in fact, had no real physical support and it appeared necessary to check it. A study driven by the mean of the integral method [30] concluded that it is acceptable for the computation of $\mathrm{h}$, but is not adequate for the description of the dynamical field. It was shown that $\delta / \delta_{\mathrm{T}}$ depends on $\mathrm{Pr}$, and a relation $\delta / \delta_{\mathrm{T}}=\Omega(\operatorname{Pr})$ was proposed for a large range of Prandtl numbers.

\section{Evolution of Boundary Layers [33]}

In natural convection, dynamical and thermal fields are linked, so that transient phenomena are of special interest. A panel of results is presented below; all of them have been got from the integral method.

On fig. 3.2, dynamical boundary layer thickness is plotted at different times, in the case of a wall heat flux $\varphi_{w}=100 \mathrm{~W} / \mathrm{m} 2$ in initially quiescent water $(\operatorname{Pr}=7)$. As predicted by other authors, the transients in free convection are found to start as a one-dimensional conduction process, to be terminated by the arrival of the leading edge effect. This is the reason why the viscous layer profiles present a flat vertical shape in the early transient. Fig.3.3. is a plot of velocity at the chosen elevation $\mathrm{x}=0.10 \mathrm{~m}$ within the viscous boundary layer where the velocity distributions are shown to increase in time to reach a steady profile in close agreement with the commonly presented shape in literature.

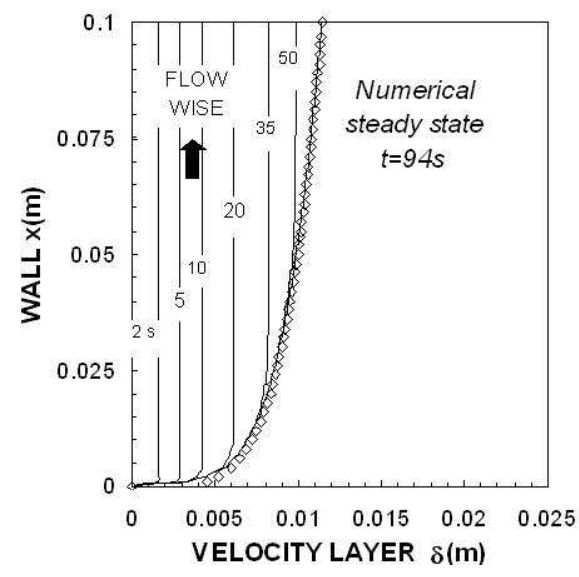

Figure 3.2. Transient behaviour of the velocity boundary layer.

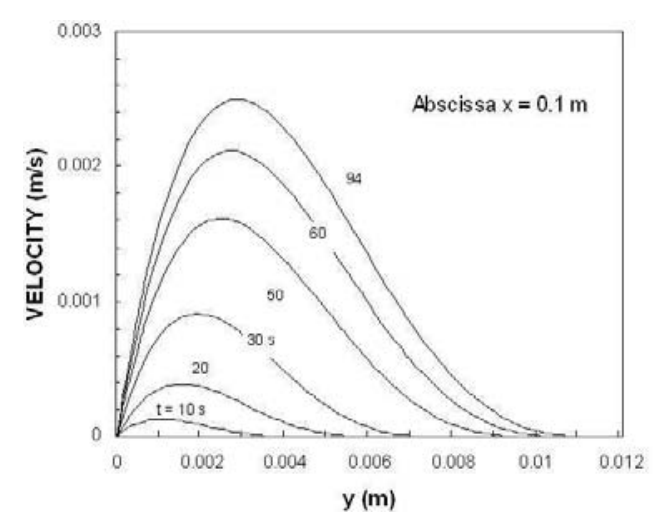

Figure 3.3. Transient velocity profiles at the $x=0.1 \mathrm{~m}$ abscissa.

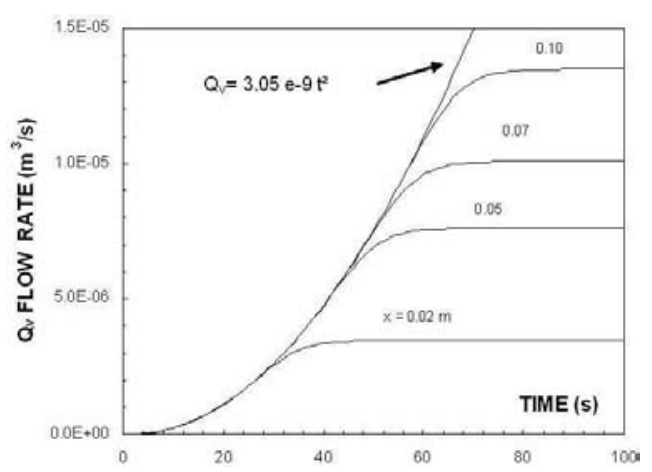

Figure 3.4. Volumetric flow rate versus time.

To complete this hydrodynamic analysis, variations of the volumetric flow rate with position and time have been investigated. Thus the integral formulation indicates that the flow rate grows downstream as $\mathrm{x}^{0.8}$. It is worth mentioning from fig. 3.4 that whatever the $\mathrm{x}$-position, before reaching its asymptotical value, the transient volumetric flow rate evolves in time as $\mathrm{t}^{2}$.

\section{Dimensioned Versus Dimensionless Results}

As it was mentioned in the second part (forced convection, $\S$ 2.2.4.5), dimensionless laws can suggest trends very different from dimensional ones. Another illustration applied to natural convection can be found in [34]. It concerns the time-dependence of the heat transfer coefficient for a panel of usual fluids.

Free Convection Around Cylinders Mounted on a Plate [35, 36]

Flow visualisation is a very efficient experimental meaning to get information on the dynamical behaviour of fluid flows. Two kinds of techniques were employed to get streamlines in the meridian section of the flow. The first one is based on an electrolytic precipitation method leading to the generation of white smoke composed of metallic salt used as a tracer material. In the experiments, electrolysis of water is made by applying a voltage between a tin wire considered as an anode, and a copper plate inside the water tank as a cathode. For the second one, the fluid is seeded with suspended fine rilsan particles $(75<$ diameter $<150 \mu \mathrm{m}, \rho=$ $1.06 \mathrm{~g} / \mathrm{cm} 3$ ) illuminated by a laser sheet ( $2 \mathrm{~W}$ argon laser) from which instantaneous integrated streamlines can be drawn.

Two applications of these techniques are reported here and in $\S$ 3.4 .5 . 
The first study describes experiments on flow visualization and local convective heat transfer of three-dimensional cylinders embedded in a transient natural boundary layer under uniform wall heat flux condition (fig. 3.5 and 3.6).

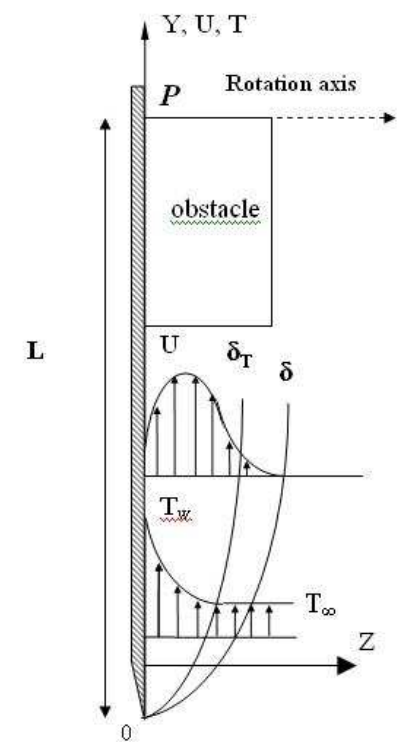

Figure. 3.5. Schematic of the experimental model.

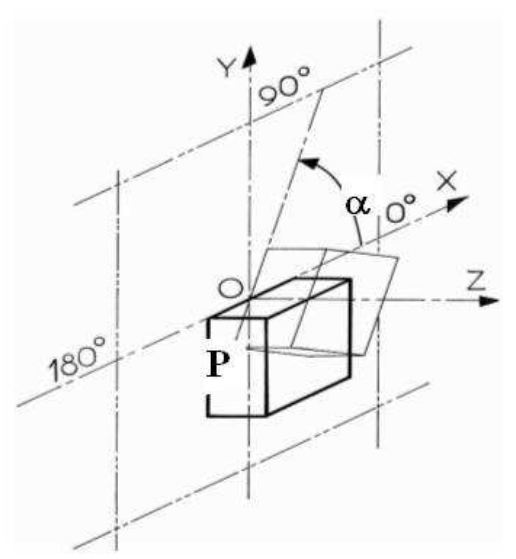

Figure 3.6. Angular positions of a square cylinder.

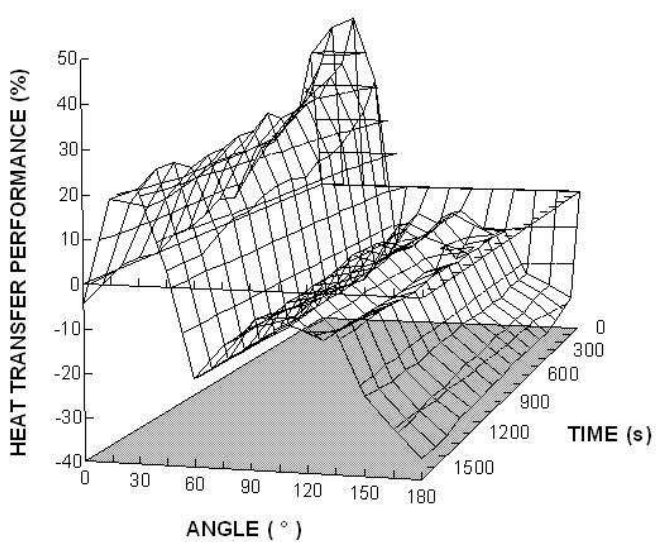

Figure 3.7. Heat transfer performance of a square cylinder compared with the smooth plate.
Especially, emphasis is put on the influence of the angular positions of the cylinder around a given axis and on its square or circular geometry on both local thermal measurements and flow patterns. For example, it is shown that for the square cylinder, a $60^{\circ}$ position induces a singular behaviour by reducing the convective heat transfer coefficient (fig.3.7); this singularity is confirmed with visualisations of the separation region.

To have an idea of the near wake shape, in fig.3.8 are presented examples in the symmetrical $(\mathrm{P}, \mathrm{Y}, \mathrm{Z})$ plane. Details are seen from metallic salts emitted from both downstream and upstream the obstacle. One can see the separation area downstream and the development of vortical structures just behind the bluff body.
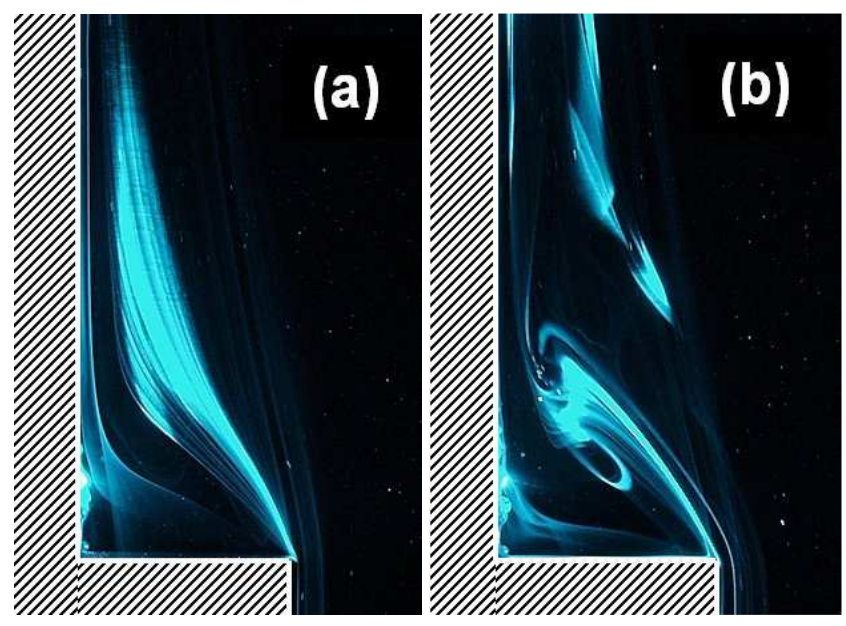

Figure 3.8. Details of the near wake for $\alpha=0$ at two times $t=120 \mathrm{~s}$ (a) and $t$ $=170 \mathrm{~s}(\mathrm{~b})$.

\section{Free Convection Along Large - Scale Roughness Plate [37]}

Moreover, transient natural convection on a vertical ribbed wall has been studied experimentally with a wall - boundary condition of uniform heat flux. This situation is of importance to both fundamental scientific research in understanding the interaction between large-scale flow features and local heat transfer, and practical interest in many industrial applications such as electronic equipment or climate control within building interiors where passive heating and cooling techniques are employed.

To get an idea about the roughness geometry influence on the heat transfer, several distinctive ribbed geometries were tested (denoted as I, II, III on fig. 3.9 and 3.10). The experimental analysis is deduced from both flow field visualisations and thermal measurements. It is shown that instantaneous flow patterns result in complex eddy structures in the vicinity of the ribs. As well vortex birth as vortex shedding process are evidenced during the transient in the open cavities between the ribs to evolve increasing time towards 3D turbulent structures. Whatever the arrangements and the time, one observe a degradation of the convective heat transfer below the first rib and an enhancement past the last one compared to the smooth case. In the open cavities, conclusions are contrasted: during the early transient an important heat transfer enhancement occurs in the upstream part of the cavity while increasing time reduces the heat transfer performance in the whole cavity. 


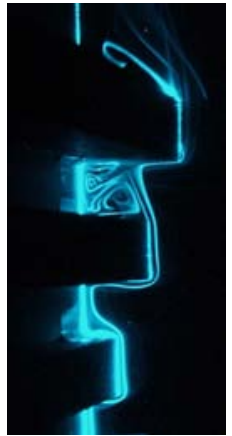

I

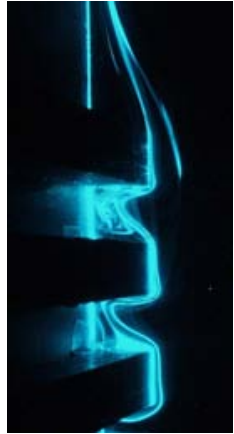

II

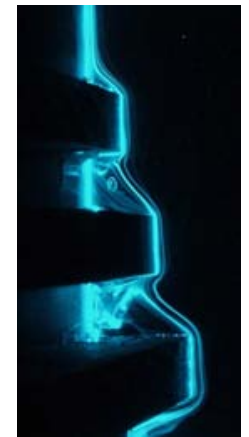

III
Figure 3.9. Streakline patterns visualised with an electrolytical precipitation method $(t=300 s)$.

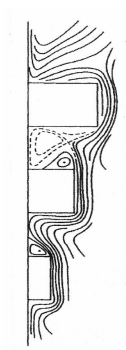

(I)

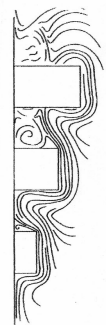

(I)

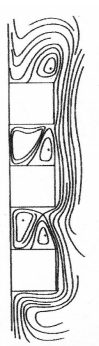

(II)

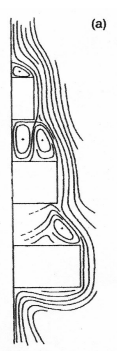

(III)

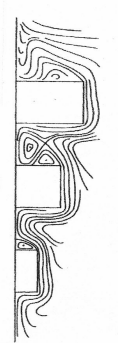

(I)

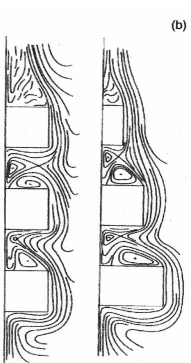

(III)
Figure 3.10. Instantaneous streamlines: (a) $t=57 \mathrm{~s}$; (b) $t=112 \mathrm{~s}$; (c) $t=610$ s. Right below: detail of the rotational flow in the lower cavity, configuration (II), $\mathrm{t}=112 \mathrm{~s}$.

\section{Mixed Convection}

\section{Introduction}

Unsteady mixed convection problems can occur in various thermal systems, either occasionally or when the boundary conditions are normally changing with time. The first kind of situations can be met in starting processes, or accidental transients, regarding for example security in power plants and electric transformers. In the second one, interest is stimulated by the needs of regulation of heat transfer equipment, as hot water heating systems in buildings.

Publications reported here deal with computational studies on water flows in vertical pipes, especially when steps of temperature or flow rate are imposed at the entrance (fig. 4.1). Two methods have been employed, either by using the classical parameters $(\S 4.2)$ or by introducing the vorticity function $(\S 4.3)$. The first formulation is more usual, but the second one suits better for describing reverse flows, and does not need any assumption on the pressure term.

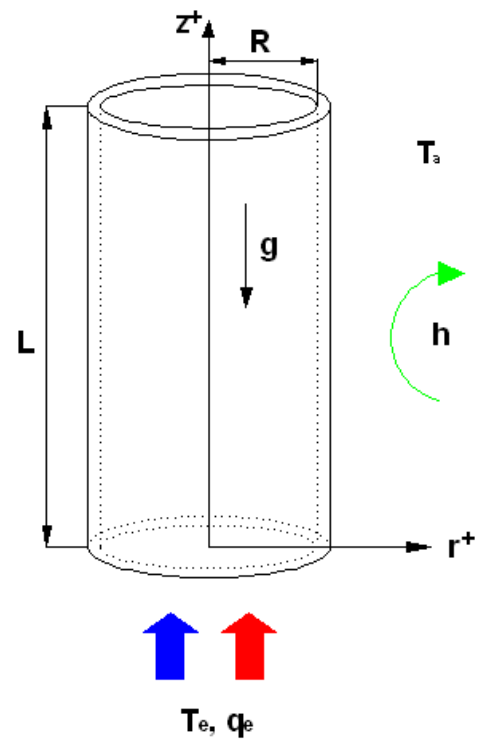

Figure 4.1. Schematic of the mixed convection model.

\section{Direct Solution Method [38, 39]}

The physical system under consideration is a vertical pipe of radius $\mathrm{R}$. The $\mathrm{z}$ axis is chosen to follow the flow direction (upward or downward). The fluid is considered to be newtonian with constant dynamic viscosity, conductivity, specific heat capacity and expansion coefficient. Density variations are assumed to be negligible except in the buoyancy term of the vertical momentum equation (Boussinesq approximation). So the problem can be formulated by the governing equations, expressed by the mean of cylindrical coordinates: continuity, axial-momentum and energy.

$$
\begin{gathered}
\frac{\partial \mathrm{U}}{\partial \mathrm{z}}+\frac{\mathrm{V}}{\mathrm{r}}+\frac{\partial \mathrm{V}}{\partial \mathrm{r}}=0 \\
\frac{\partial \mathrm{U}}{\partial \mathrm{t}}+\mathrm{U} \frac{\partial \mathrm{U}}{\partial \mathrm{z}}+\mathrm{V} \frac{\partial \mathrm{U}}{\partial \mathrm{r}}=-\frac{1}{\rho} \frac{\partial \mathrm{p}^{*}}{\partial \mathrm{z}}+\operatorname{\varepsilon g} \beta\left(\mathrm{T}_{\mathrm{e}}-\mathrm{T}_{\mathrm{w}}\right)+\mathrm{v}\left(\frac{1}{\mathrm{r}} \frac{\partial \mathrm{U}}{\partial \mathrm{r}}+\frac{\partial^{2} \mathrm{U}}{\partial \mathrm{r}^{2}}\right) \\
\frac{\partial \mathrm{T}}{\partial \mathrm{t}}+\mathrm{U} \frac{\partial \mathrm{T}}{\partial \mathrm{z}}+\mathrm{V} \frac{\partial \mathrm{T}}{\partial \mathrm{r}}=\alpha\left(\frac{1}{\mathrm{r}} \frac{\partial \mathrm{T}}{\partial \mathrm{r}}+\frac{\partial^{2} \mathrm{~T}}{\partial \mathrm{r}^{2}}\right)
\end{gathered}
$$

with $\mathrm{p}^{*}=\mathrm{p}-\rho \mathrm{gz} ;$ upward flow $: \varepsilon=+1$; downward flow $: \varepsilon=-1$

The physical problem is characterised by the following initial and boundary conditions:

- thin pipe wall

- on the outer surface of the pipe: averaged free convection heat transfer, so that the wall heat flux is:

$$
\varphi_{\mathrm{w}}=\mathrm{h}\left(\mathrm{T}_{\mathrm{w}}-\mathrm{T}_{\infty}\right)
$$

- on the inner surface $(r=R)$ :

$$
\mathrm{U}=\mathrm{V}=0
$$

- on the axis $(r=0)$ :

$$
\frac{\partial \mathrm{U}}{\partial \mathrm{r}}=\frac{\partial \mathrm{T}}{\partial \mathrm{r}}=0
$$


- at the entrance $(z=0)$ : fully developed velocity profile $\mathrm{U}_{\mathrm{o}}$ and injection temperature $\mathrm{T}_{\mathrm{e}}$ :

- $\quad \mathrm{t}<0$ : flow rate $\mathrm{q}_{\mathrm{o}}$; Reynolds $\mathrm{Re}_{\mathrm{o}}$, temperature $\mathrm{T}_{0}$

- $\mathrm{t} \geq 0$ : flow rate $\mathrm{q}_{\mathrm{e}}=\mathrm{q}_{\mathrm{o}}+\Delta \mathrm{q}_{\mathrm{e}}\left(\Delta \mathrm{q}_{\mathrm{e}}>0\right.$ or $\left.<0\right)$, i.e. $\operatorname{Re}_{\infty}$ $=\operatorname{Re}_{\mathrm{o}}+\Delta \mathrm{Re}$

and / or temperature $\mathrm{T}_{\mathrm{e}}=\mathrm{T}_{0}+\Delta \mathrm{T}_{\mathrm{e}}\left(\Delta \mathrm{T}_{\mathrm{e}}>0\right.$ or $\left.<0\right)$

- at the exit $(\mathrm{z}=\mathrm{L}): \partial \mathrm{U} / \partial \mathrm{z}=0$

Equations were solved by a finite-difference, fully implicit procedure. The pressure gradient was written as the sum of a steady term and of a time - dependent term in relation with the flow rate conservation [39].

\section{Vorticity Method [40, 41]}

The situation considered is a laminar flow upward through a vertical pipe, that is imposed by a heat transfer coefficient on the outer surface of the pipe. Flow entering the pipe is solicited by a temperature step. In this part, governing equations are formulated in terms of the stream function $\Psi$ and the vorticity $\Omega$, with the following dimensionless quantities:

$$
\begin{gathered}
r^{+}=\frac{r}{R} \quad ; \quad z^{+}=\frac{z}{R} \quad ; \quad U^{+}=\frac{U}{V_{d}} ; V^{+}=\frac{V}{V_{d}} ; T^{+}=\frac{T-T_{a}}{T_{e}-T_{a}} \\
t^{+}=\frac{V_{d} t}{R} \quad ; \quad \Omega^{+}=\frac{\Omega R}{V_{d}} ; \psi^{+}=\frac{\psi}{V_{d} R^{2}} \\
U^{+}=-\frac{1}{r^{+}} \frac{\partial \psi^{+}}{\partial z^{+}} \quad ; \quad V^{+}=\frac{1}{r^{+}} \frac{\partial \psi^{+}}{\partial r^{+}} ; \Omega^{+}=\frac{\partial U^{+}}{\partial z^{+}}-\frac{\partial V^{+}}{\partial r^{+}}
\end{gathered}
$$

The non-dimensional equations in terms of these variables and temperature are :

$$
\begin{gathered}
-\Omega^{+}=\frac{\partial}{\partial r^{+}}\left(\frac{1}{r^{+}} \frac{\partial \psi^{+}}{\partial r^{+}}\right)+\frac{1}{r^{+}} \frac{\partial^{2} \psi^{+}}{\partial z^{+2}} \\
\frac{\partial \Omega^{+}}{\partial t^{+}}+\frac{\partial\left(\Omega^{+} V^{+}\right)}{\partial z^{+}}+\frac{\partial\left(\Omega^{+} U^{+}\right)}{\partial r^{+}}=\frac{1}{R e}\left[\frac{1}{r^{+}} \frac{\partial}{\partial r^{+}}\left(r^{+} \frac{\partial \Omega^{+}}{\partial r^{+}}\right)+\frac{\partial^{2} \Omega^{+}}{\partial z^{+2}}\right]+R i \frac{\partial T^{+}}{\partial r^{+}} \\
\frac{\partial T^{+}}{\partial t^{+}}+\frac{1}{r^{+}} \frac{\partial\left(r^{+} U^{+} T^{+}\right)}{\partial r^{+}}+\frac{\partial\left(V^{+} T^{+}\right)}{\partial z^{+}}=\frac{1}{P e}\left[\frac{1}{r^{+}} \frac{\partial}{\partial r^{+}}\left(r^{+} \frac{\partial T^{+}}{\partial r^{+}}\right)+\frac{\partial^{2} T^{+}}{\partial z^{+2}}\right]
\end{gathered}
$$

The initial and boundary conditions are as follows:

$$
t^{+}<0,0 \leq z^{+} \leq 1,0 \leq r^{+} \leq 1: T^{+}=1 \text { (uniform temperature) }
$$
$t^{+} \geq 0$,

$$
z^{+}=0: \quad \psi^{+}=r^{+}\left(1-\frac{r^{+2}}{2}\right)-\frac{1}{2} ; \Omega^{+}=4 r^{+} ; T^{+}=1+\Delta T^{+}
$$

where $\Delta T^{+}=\frac{\Delta T_{e}}{T_{e}-T_{a}} \quad\left(\Delta T^{+}>0\right.$ or $\left.<0\right)$

$$
\begin{gathered}
r^{+}=0: \quad \frac{\partial T^{+}}{\partial r^{+}}=\frac{\partial \psi^{+}}{\partial r^{+}}=0 ; \quad \Omega^{+}=0 \\
r^{+}=1: \quad \psi^{+}=0 ;\left(\frac{\partial T^{+}}{\partial r^{+}}\right)_{w}=-B i^{*} T_{w}^{+}
\end{gathered}
$$

where $B i^{*}=\frac{h_{a} R}{\lambda_{f}}$ (generalised Biot number $)$

The foregoing equations were solved by a finite - difference procedure, with an explicit numerical scheme [41].

\section{Applications}

\section{Temperature Steps at the Entrance [41]}

As an application of the vorticity method, the following conditions were selected: upward water flow, pipe of diameter 20 $\mathrm{mm}$, bulk velocity $=0.045 \mathrm{~m} / \mathrm{s}$. On the external surface, authors assumed a constant mean coefficient $h_{a}=5 \mathrm{~W} / \mathrm{m}^{2} . \mathrm{K}$, with ambient air at $\mathrm{T}_{\mathrm{a}}=20^{\circ} \mathrm{C}$.

Regarding the case where $\Delta \mathrm{T}_{\text {inlet }}=+10{ }^{\circ} \mathrm{C}$, velocity and temperature profiles have been plotted on fig. 4.2, at a distance from the entrance $\mathrm{z}=200 \mathrm{~mm}$. A short time after the perturbation, under buoyancy effect the fluid velocity increases in the central part and decreases near the wall, with an invariant point at $\mathrm{r}^{+} \approx 0.66$; the distortion is maximal at about $11 \mathrm{~s}$, and can lead to reverse flow.

In the case of a negative step $\left(\Delta \mathrm{T}=-10{ }^{\circ} \mathrm{C}\right.$, fig. 4.3$)$ the velocity profile shows another kind of distortion, with a fluid velocity increasing first near the wall and decreasing in the central part. The perturbation reaches its maximum value sooner (at $\mathrm{t} \approx 9 \mathrm{~s}$ ) and is stronger with increasing distance from the entrance.
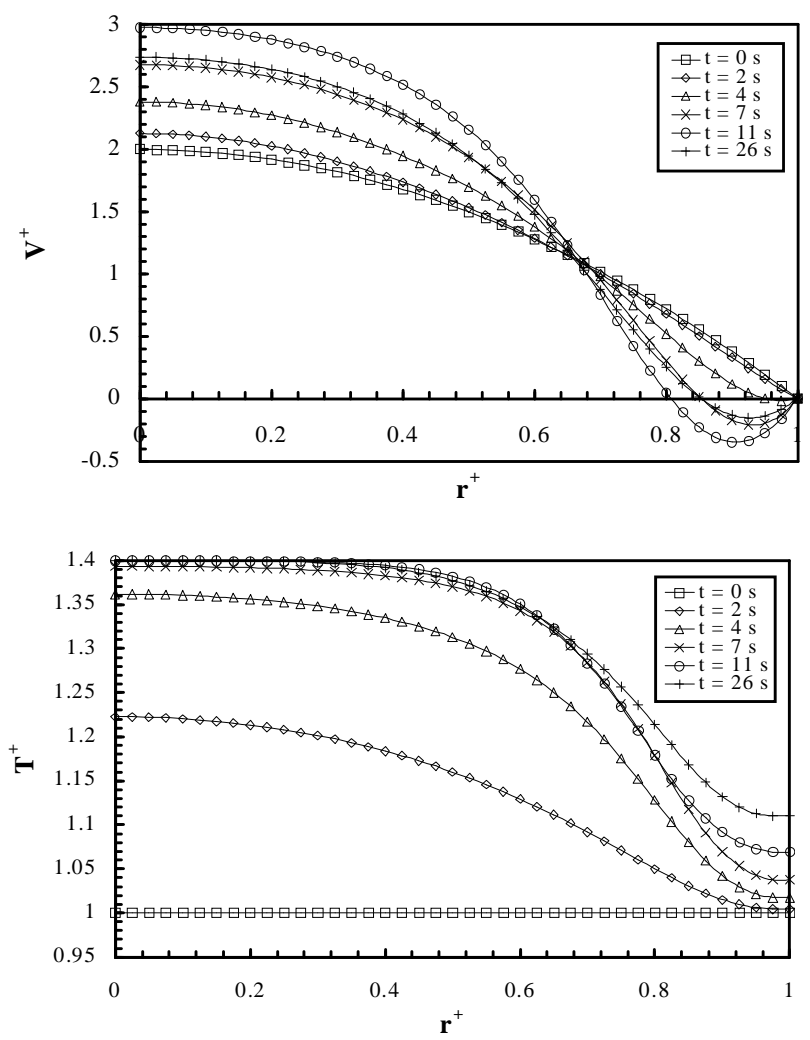

Figure 4.2. Velocity and temperature profiles for $z=200 \mathrm{~mm}, \Delta \mathrm{T}=+10^{\circ} \mathrm{C}$. 

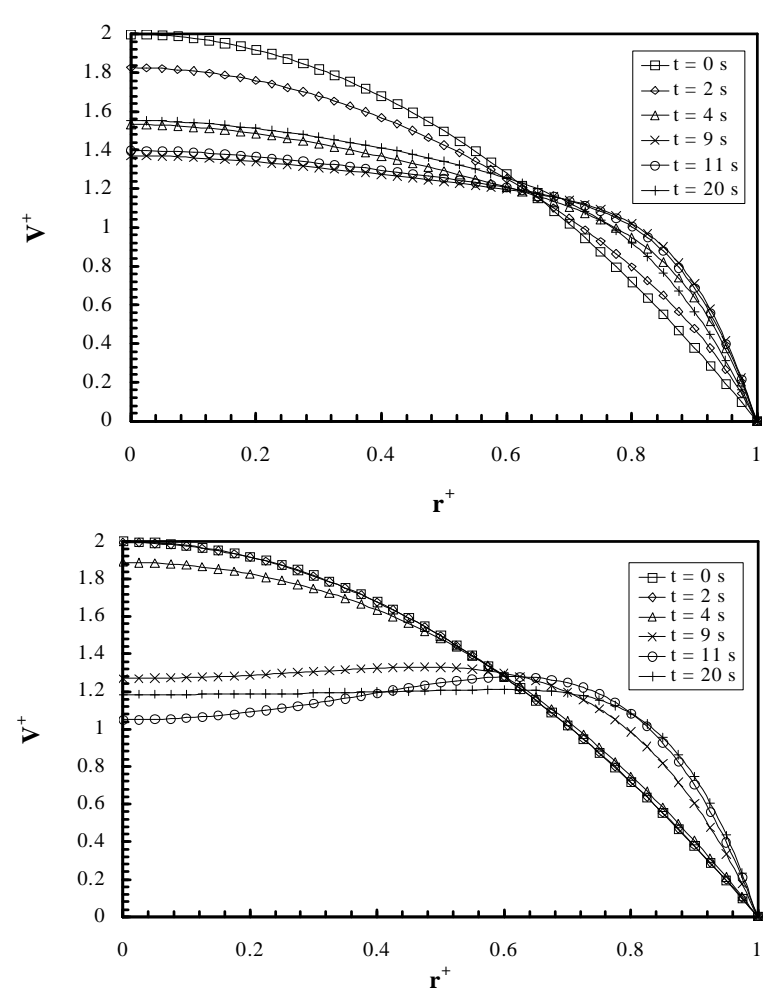

Figure 4.3. Velocity profiles for $z=200 \mathrm{~mm}$ (left) and $z=600 \mathrm{~mm}$ (right), $\Delta T$ $=-10^{\circ} \mathrm{C}$.

\section{Flow Rate Steps [39, 42]}

Using direct solution method, other studies have dealt with flow rate steps, positive or negative (fig. 4.4 and 4.5). In such circumstances, perturbations in the velocity field are rather progressive with an increase of flow rate, but more complex in the case of negative steps. Computations show also that the response is slower with negative steps (fig. 4.6) as the contrary was observed with temperature steps. Moreover, the buoyancy ratio RiRe has a strong influence on the wall heat transfer [42].

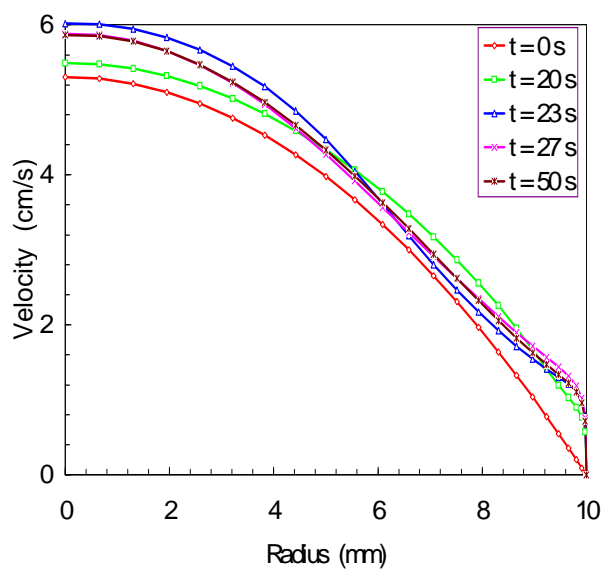

Figure 4.4. Velocity and temperature profiles for different times at $z$ $=300 \mathrm{~mm} \Delta \mathrm{q}_{\mathrm{v}}=+5 \mathrm{l} / \mathrm{h} ; \mathrm{T}_{\mathrm{e}}=40^{\circ} \mathrm{C} ; \operatorname{Re}_{\circ}=530 ; \mathrm{Re}_{\infty}=620 ; \mathrm{Gr}=3.105$; $\operatorname{RiRe}_{\infty}=484$.

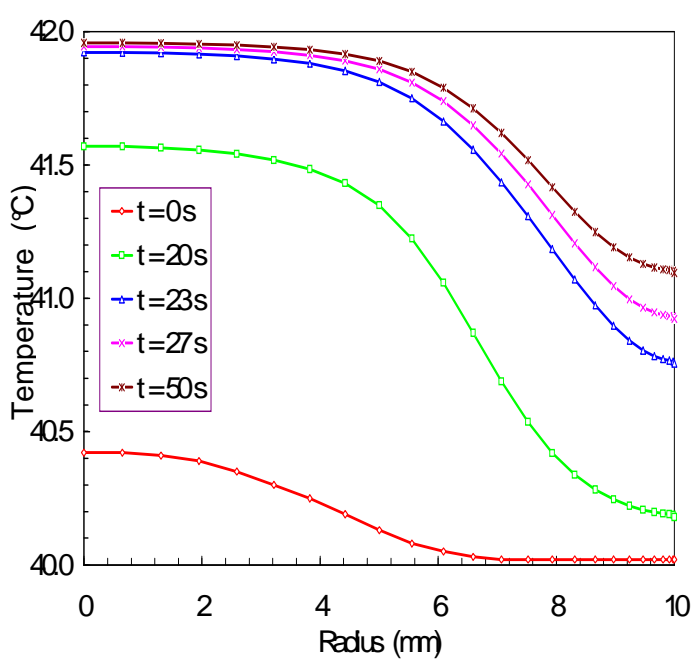

Figure 4.4. (Continued).
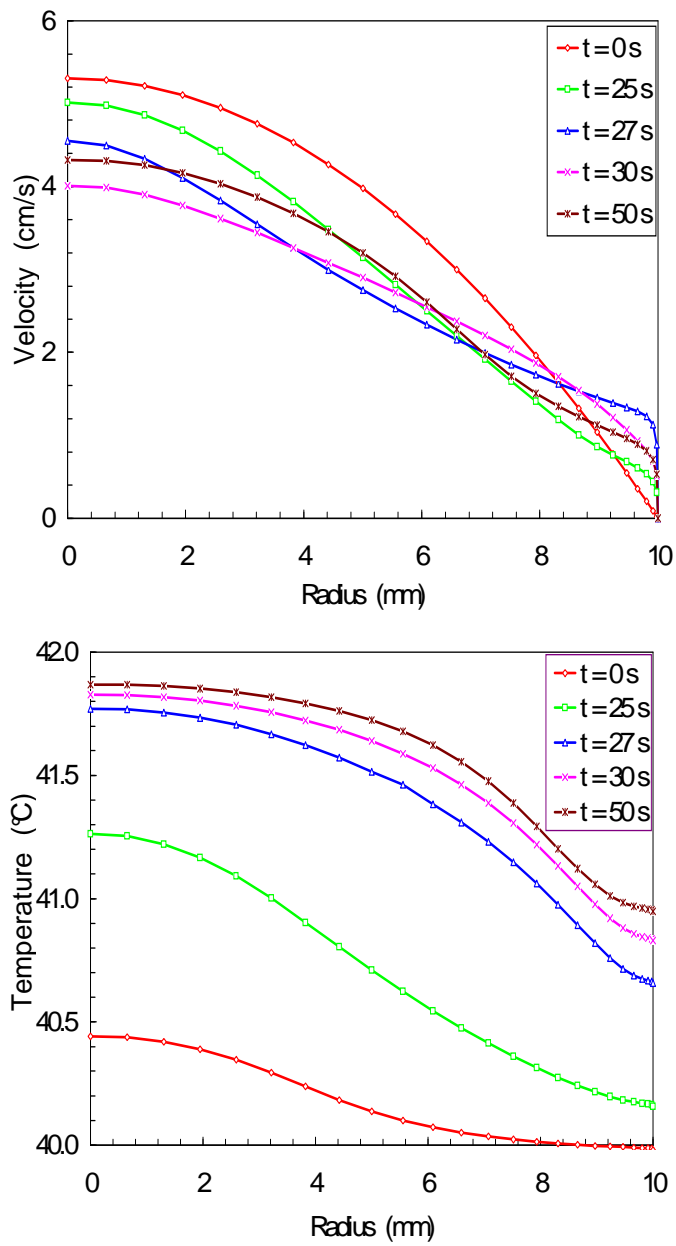

Figure 4.5. Velocity and temperature profiles for different times at $z$ $=300 \mathrm{~mm} \Delta \mathrm{q}_{\mathrm{v}}=-5 \mathrm{l} / \mathrm{h}$; other variables unchanged. 


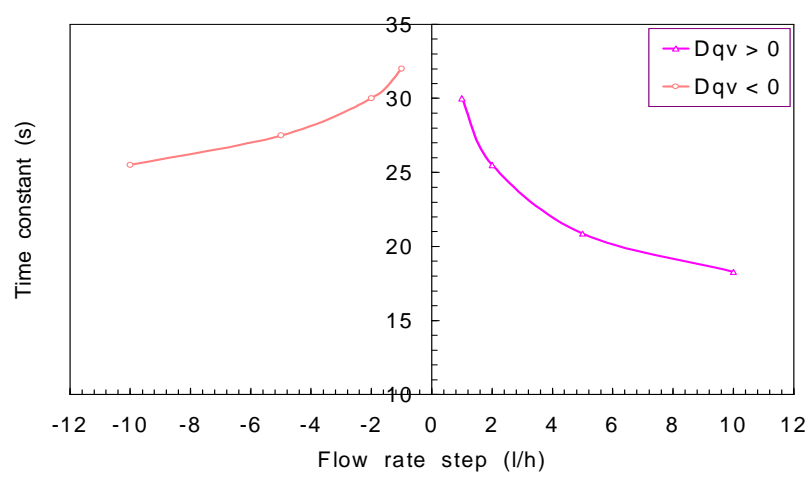

Figure 4.6. Time constant evolution for positive and negative flow rate steps at $z=400 \mathrm{~mm} ; \operatorname{Re}=530 ; T_{0}=40^{\circ} \mathrm{C}$.

\section{Combined Temperature and Flow Rate Steps}

Unfortunately, combined temperature and flow rate steps have not been widely investigated, despite of their special interest as they can lead to amplified or smoothed effects, depending on their sign and amplitude. Examples plotted on fig. 4.7 to 4.9 come from ref. [43] and show in a special case that the friction factor along the wall is more regular when the two steps are positive.
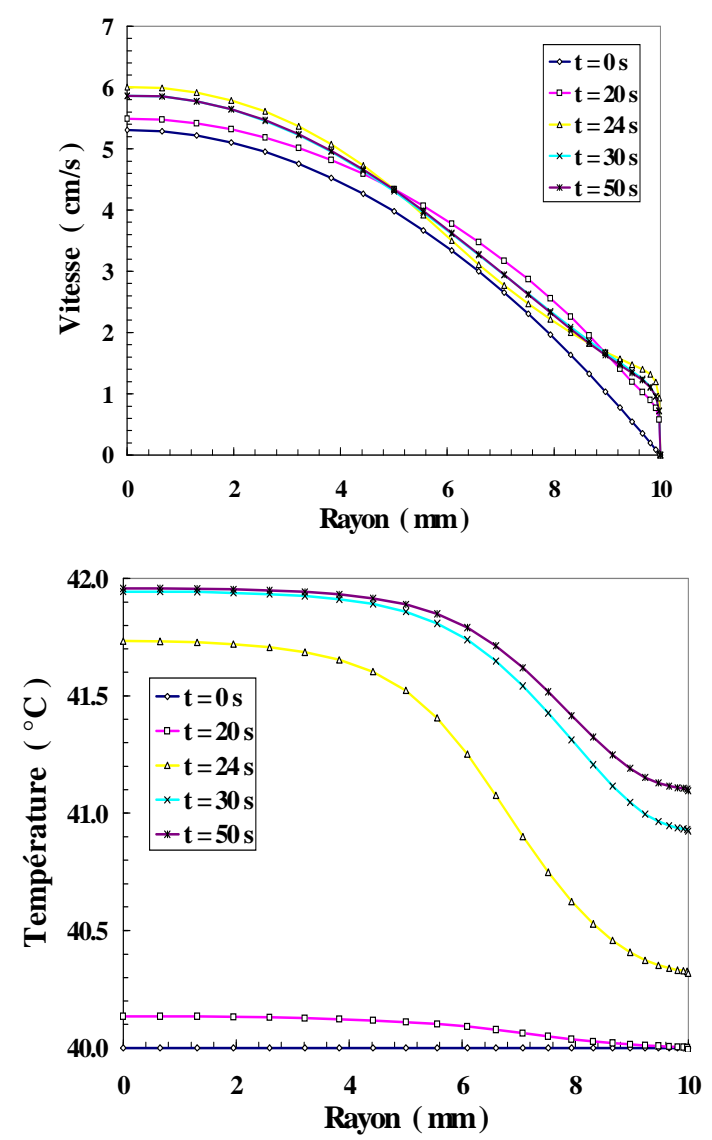

Figure 4.7. Velocity and temperature profiles at $\mathrm{z}=300 \mathrm{~mm} ; \Delta \mathrm{q}_{\mathrm{v}}=+5.10^{-3}$ $\mathrm{m}^{3} / \mathrm{h}, \Delta \mathrm{T}=+2^{\circ} \mathrm{C}, \mathrm{qv}_{\mathrm{o}}=3.10^{-2} \mathrm{~m}^{3} / \mathrm{h}, \mathrm{T}_{\mathrm{eo}}=40^{\circ} \mathrm{C}, \mathrm{h}_{\mathrm{a}}=10 \mathrm{~W} / \mathrm{m}^{2} . \mathrm{K}$.
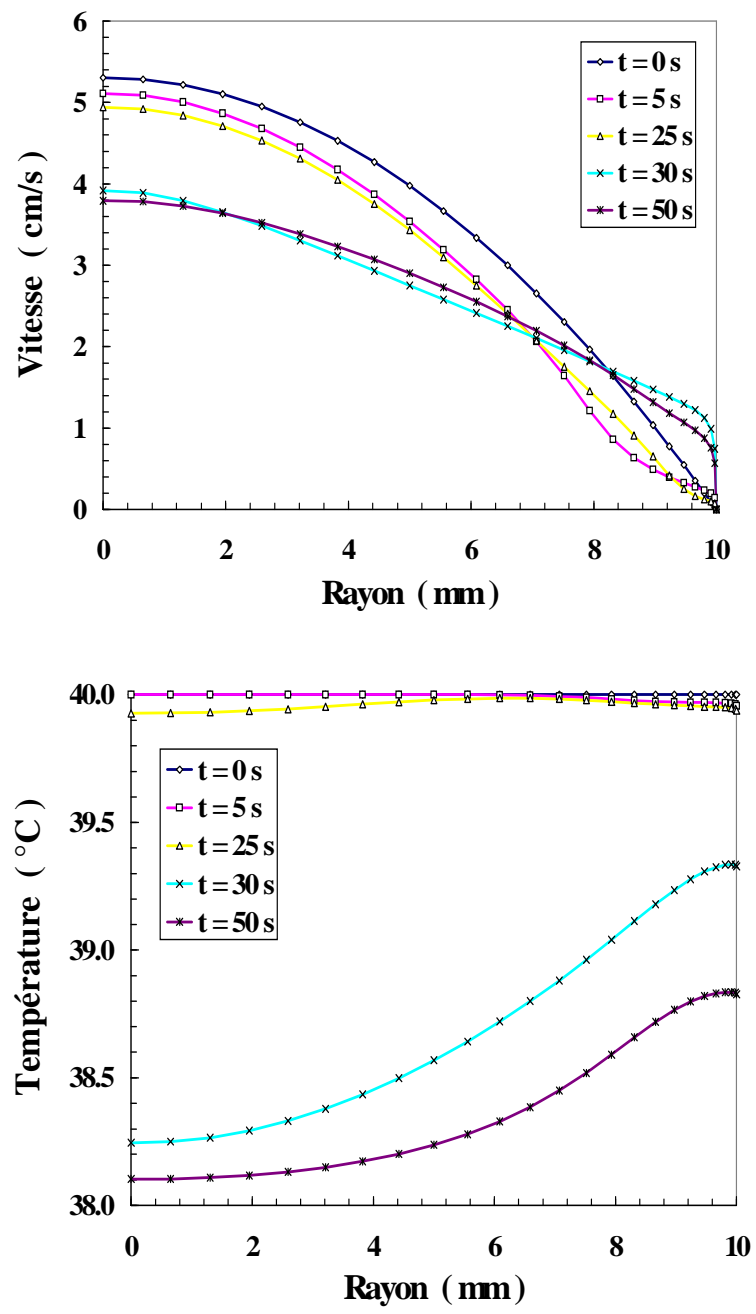

Figure 4.8. Same datas as on fig. 4.7. except $\Delta q_{v}=-5.10^{-3} \mathrm{~m}^{3} / \mathrm{h}$; $\Delta \mathrm{T}=-2^{\mathrm{C}} \mathrm{C}$.

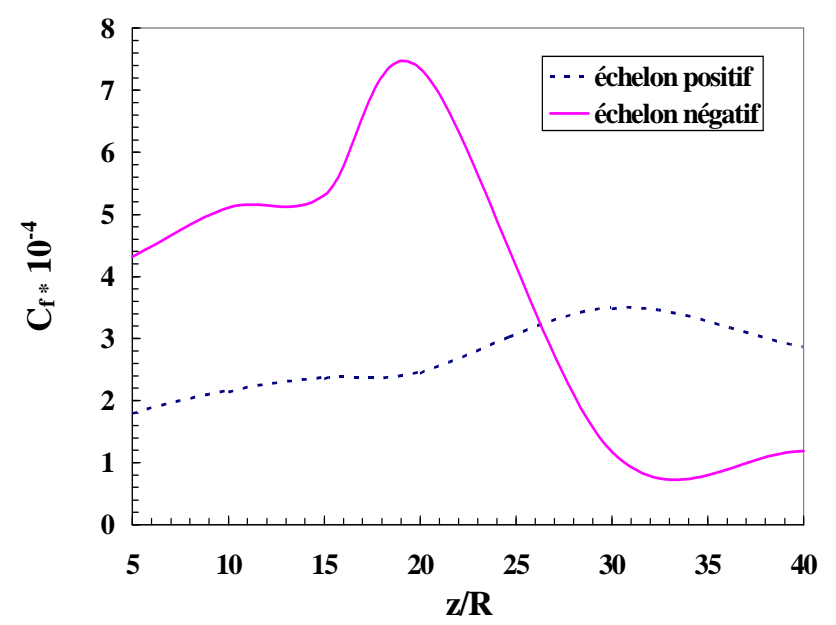

Figure 4.9. Friction factor along the pipe..... : same datas as fig. 4.7. ; --.-- : fig. 4.8. 


\section{Flow Instabilities $[44,45]$}

Very interesting complementary informations on the structure of the flow are brought by streamlines and isotherms [44], as they specially permit to observe reverse flows and vortex that can occur during the transient (see examples on fig. 4.10 and 4.11). These structures are of practical interest because of their influence on friction and heat transfer at the wall, but also of fundamental importance, as they can be considered as signs of instability.

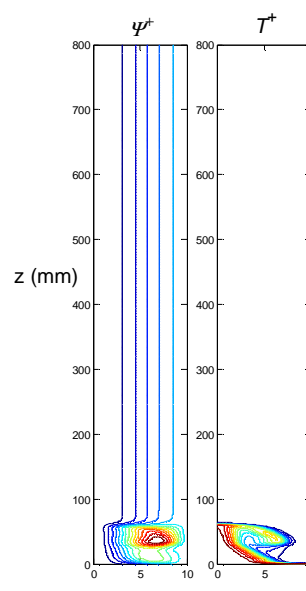

(a)

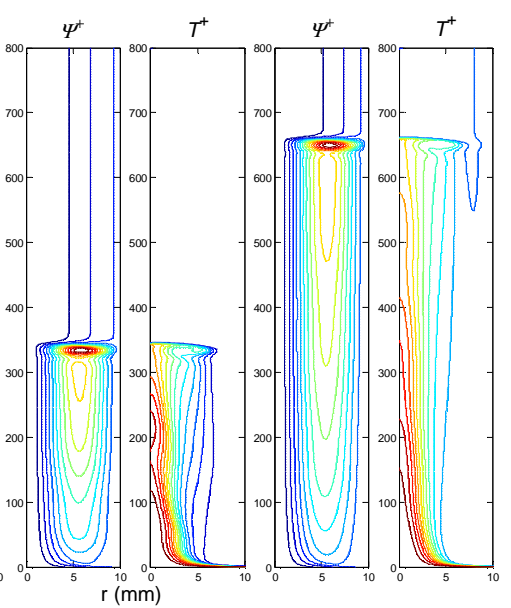

(b)

(c)
Figure 4.10. Time development of streamlines and isotherms along the pipe for $\Delta T=+10^{\circ} \mathrm{C},(\mathrm{a}): 5 \mathrm{~s},(\mathrm{~b}): 15 \mathrm{~s}$ and (c): $25 \mathrm{~s}$.

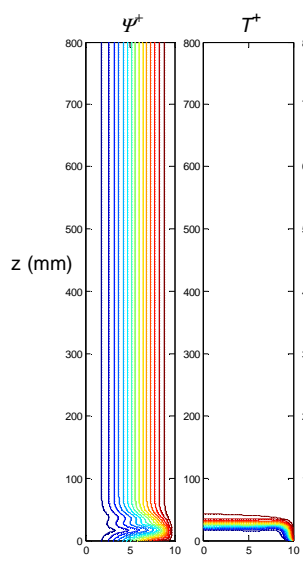

(a)

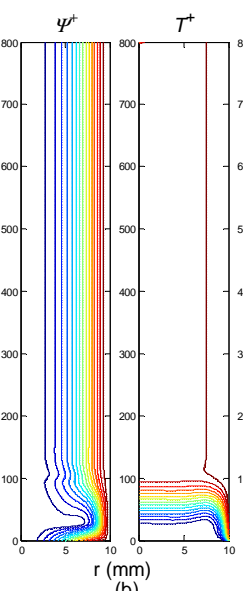

(b)

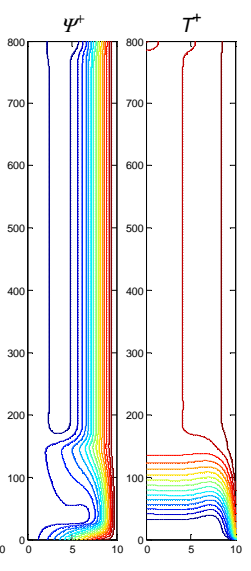

(c)
Figure 4.11. Time development of streamlines and isotherms along the pipe for $\Delta T=-10^{\circ} \mathrm{C},(\mathrm{a}): 10 \mathrm{~s},(\mathrm{~b}): 30 \mathrm{~s}$ and (c): $50 \mathrm{~s}$.

Indeed, stability in transient states remain a widely open issue. As a starting point, two stability diagrams were proposed in the case of an upward flow, using similitude criteria Ri and Re (fig. 4.12). They show a stable zone (free of reverse flow or vortex) larger for negative than for positive temperature steps [45].
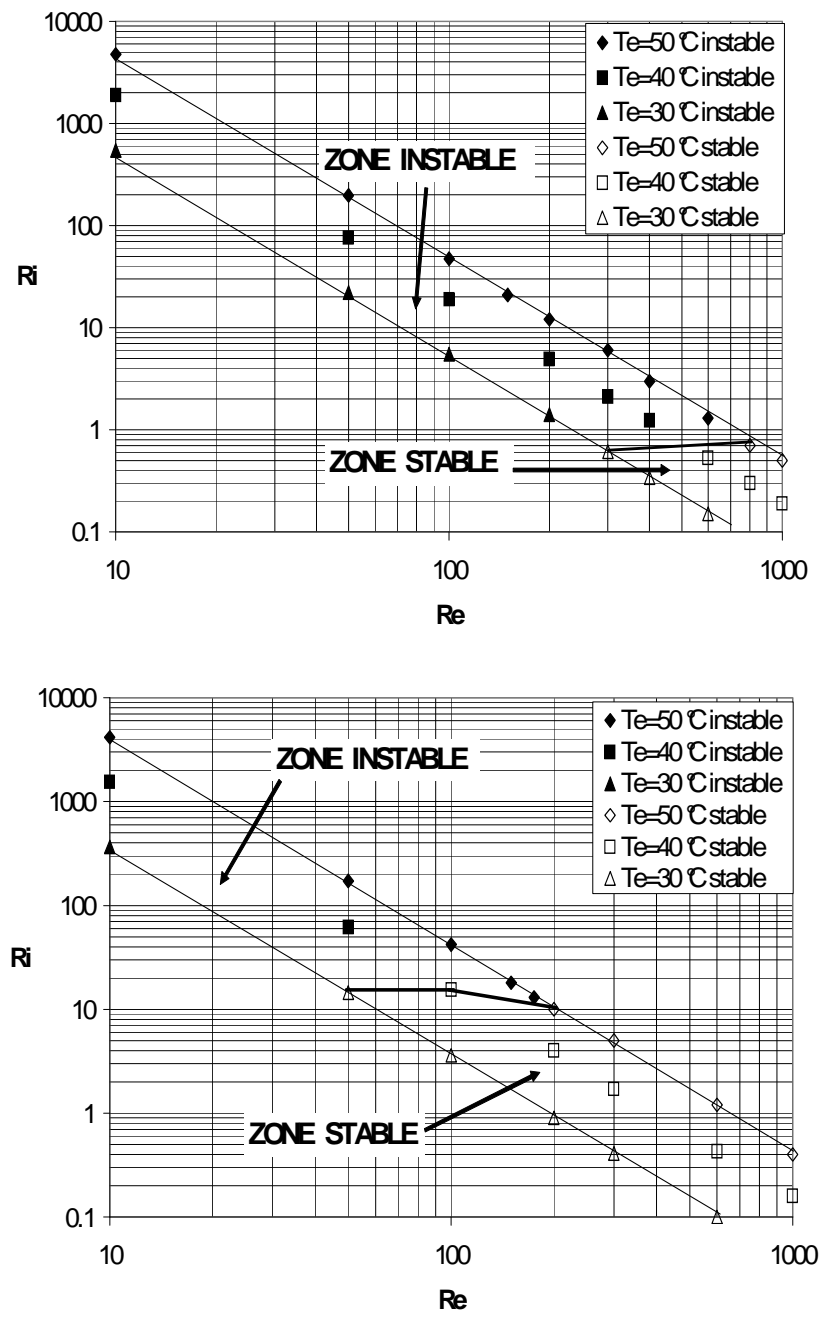

Figure 4.12. Stability diagrams $\mathrm{Ri}-\mathrm{Re}$ for $\Delta \mathrm{Te}>0$ (left) and $\Delta \mathrm{Te}<0$ (right).

\section{Mixed Convection Boundary Layers [46]}

Transient mixed convection of laminar boundary layer past a vertical plate has been also investigated, using a finite-difference procedure with fully implicit numerical scheme. Boundary conditions combined heat flux step at the wall and velocity step ( $>0$ or $<0$ ) in the external flow, taking in account the wall heat capacity, either in aiding or opposing mixed convection (fig. 4.13). Results show that, especially in the case of opposing flow, a weak perturbation of velocity can lead to instabilities near the wall. 

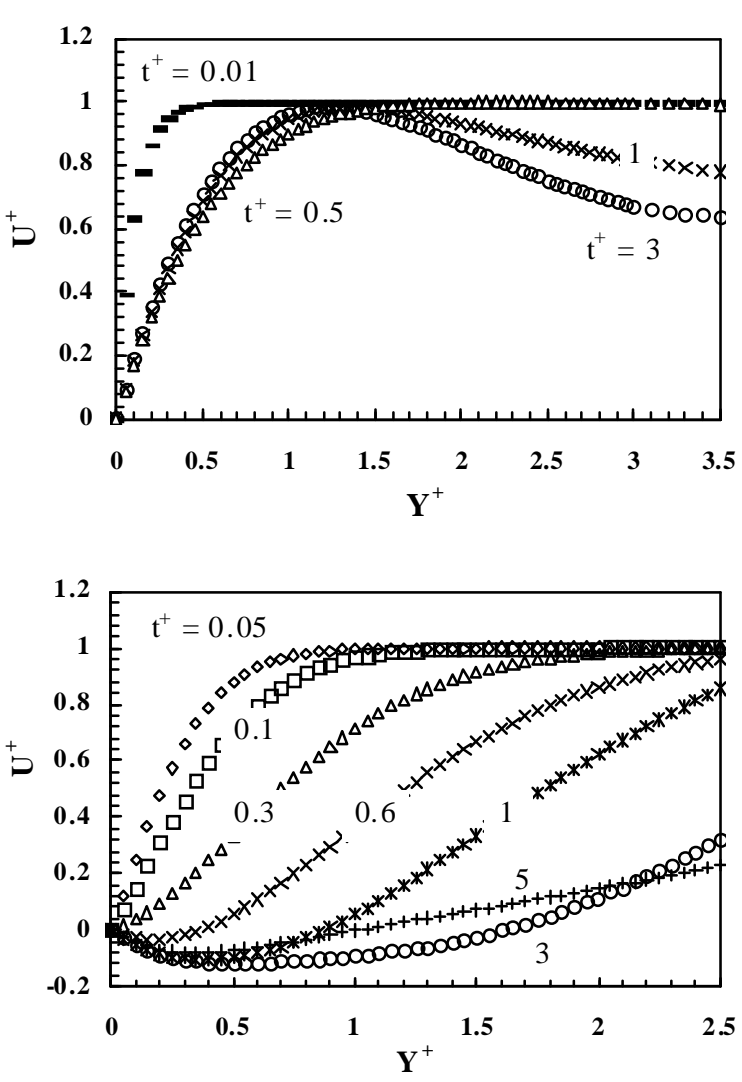

Figure 4.13. Velocity profiles at different times $\mathrm{t}^{+}$for a flow velocity step $\Delta U^{+} \operatorname{Pr}=1 ; E\left(\rho C_{p}\right)_{\text {wall }} / L\left(\rho C_{p}\right)_{\text {fluid }}=5$; left: aiding flow, $R i R e=+50, \Delta U^{+}=$ 0.4 ; right: opposing flow, $\operatorname{RiRe}=-50, \Delta U^{+}=+0.4$.

\section{Measurement of the Heat Transfer Coefficient [18] [47 To 50]}

A major practical application of transient convection deals with the measurement of heat transfer coefficients by pulsed photothermal radiometry.

The method consists of analysing the transient temperature on the front face of a wall, after a sudden deposit of luminous energy, and is generally used for non-destructive testing operations as well as measurement of thermophysical properties. But it was also proposed to consider pulsed photothermal radiometry as a tool for the measurement of convective heat transfer coefficient on the front side of the sample [47]. A scheme of the experimental device is presented on fig. 5.1.

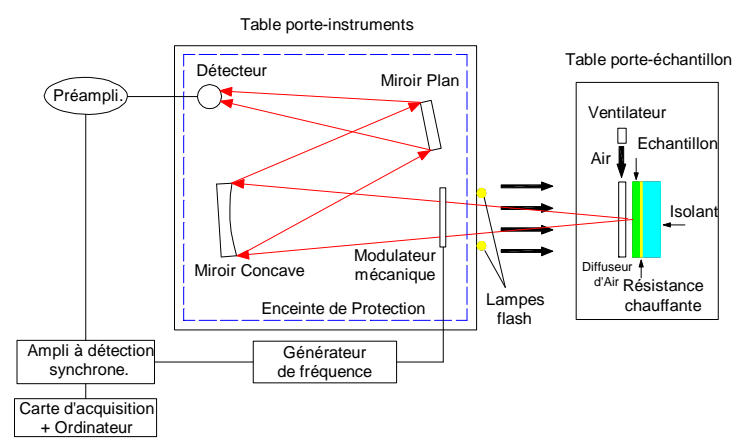

Figure 5.1. Experimental device.
A theoretical model was initially based on the assumption of a constant $\mathrm{h}$ coefficient during the transient used for the measurement. Compared to other experimental techniques as fluxmeters, the results gave rather good evaluations for $\mathrm{h}$. An extension of this method was also described, allowing to simultaneous determination of the exchange coefficients on both sides of a thermally thin wall [48].

Indeed, assuming $\mathrm{h}=\mathrm{cst}$ is not satisfactory if a precise measured value is required, and it becomes necessary to take into account that $\mathrm{h}=\mathrm{h}(\mathrm{t})$ during the measurement process. So, results obtained from transient forced convection over a thin flat plate $([6,11,18], \S 4.1)$ were used to introduce a variable coefficient $h(t)$ in the theoretical model, as an exponential function of time $[49,50)$. This study leads to the conclusion that, in an air flow, $\mathrm{h}=\mathrm{cst}$ in an adequate approximation with a dirac pulse. But in the case of finite duration pulses, this simplification is less and less valid as the duration increases (tables 5.1 and 5.2: lines 1 to 5 correspond to different values of air flow velocity, from 1.1 to $2.4 \mathrm{~m} / \mathrm{s})$, and a $\mathrm{h}(\mathrm{t})$ model gives more accurate values.

A second improvement will consist in considering the thickness and heat capacity of the plate, which modify $h(t)$ compared to the case of a thin plate $[20,23]$.

Table 5.1. Convective heat coefficient in $\left(\mathrm{W} \mathrm{m}^{-2} \mathrm{~K}^{-1}\right)$ for dirac excitation.

\begin{tabular}{|c|c|c|c|c|c|}
\hline & Fluxmeter & Model h cst & $\frac{\Delta \mathrm{h}_{\mathrm{c} 0}}{\mathrm{~h}_{\mathrm{c} 0}}$ & Model h(t) & $\frac{\Delta \mathrm{h}_{\mathrm{c} 0}}{\mathrm{~h}_{\mathrm{c} 0}}$ \\
\hline $\mathbf{1}$ & 37 & 35,2 & $-5 \%$ & 40 & $+8 \%$ \\
\hline $\mathbf{2}$ & 50 & 46,5 & $-7 \%$ & 49,5 & $-1 \%$ \\
\hline $\mathbf{3}$ & 62 & 67 & $+8 \%$ & 63,2 & $+2 \%$ \\
\hline $\mathbf{4}$ & 74 & 77 & $+4 \%$ & 71,8 & $-3 \%$ \\
\hline
\end{tabular}

Table 5.2. Convective coefficient in $\left(\mathrm{W} \mathrm{m}^{-2} \mathrm{~K}^{-1}\right)$ for $5 \mathrm{~s}$ excitation.

\begin{tabular}{|c|c|c|c|c|c|}
\hline & \multirow{2}{*}{ Fluxmètre } & Model h cst & $\frac{\Delta \mathrm{h}_{\mathrm{c} 0}}{\mathrm{~h}_{\mathrm{c} 0}}$ & Model h(t) & $\frac{\Delta \mathrm{h}_{\mathrm{c} 0}}{\mathrm{~h}_{\mathrm{c} 0}}$ \\
\hline $\mathbf{1}$ & 37 & 49 & $+32 \%$ & 42,3 & $+14 \%$ \\
\hline $\mathbf{2}$ & 50 & 65 & $+30 \%$ & 56 & $+12 \%$ \\
\hline $\mathbf{3}$ & 62 & 70,6 & $+14 \%$ & 67 & $+8 \%$ \\
\hline $\mathbf{4}$ & 74 & 80 & $+8 \%$ & 80 & $+8 \%$ \\
\hline
\end{tabular}

\section{Heat Exchangers Under Transient Conditions}

Though it is based on an overall modelling, unsteady behaviour of heat exchangers can be considered as a special case of unsteady convection. It can occur in various conditions such as natural timevarying inlet temperatures or flow rates, start-ups, shut-downs, power surges, pump failures.... So an accurate knowledge of the thermal response of such systems during unsteady periods of operation is very important for effective controls, as well as for the understanding of the adverse effects which usually result in modified thermal performances or increased thermal stresses which will ultimately produce mechanical failure.

\section{Assumptions and Modelling}

Most of previous studies have made the assumption of constant heat transfer coefficient, but generally this coefficient is time dependent in most non-stationary states. Another kind of methods that avoid the use of this coefficient during the transient phase is the two-parameter method with time lag and time constant. In fact, the experimental observation of exit temperatures when inlet temperatures or flow rates are submitted to sudden change, shows 
that they can be approximated by an exponential curve (characterised by a time constant $\tau$ ) after a time lag $\mathrm{t}_{\mathrm{r}}$ (fig. 6.1).

The model is based on the assumption that $\tau$ and $t_{r}$ do not vary inside the exchanger, and can be considered as overall characteristics of the system. Obviously, this is an approximation (indeed, it replaces $\mathrm{h}=\mathrm{cst}$ !) but it leads to elementary analytical expressions and to very good agreements with experimental results $[51,52,53]$

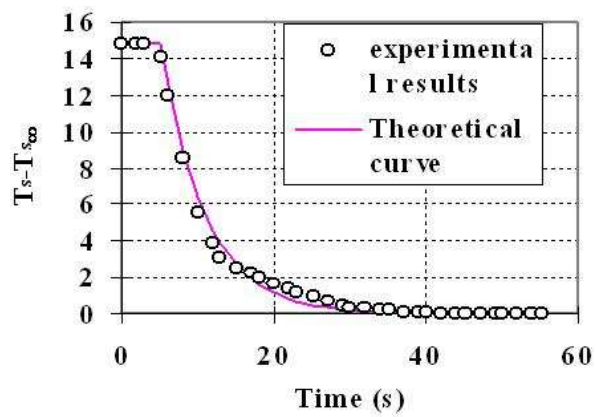

Figure 6.1. Water-water heat exchanger: example of exit temperature after a flow rate step.

\section{General Expression of the Time Constant [52, 54]}

The model describes a heat exchanger, initially working in steady state, submitted at time $t=0$ to sudden variations of inlet temperatures and/or flow rates. A new steady state is reached at $\mathrm{t}=$ $\infty$.

Several index will be used in the following formulas: "c" or " $\mathrm{h}$ " for "cold fluid" or "hot fluid", "e" or "s" for "inlet" (entrée) or "outlet" (sortie), " 0 " or " $\infty$ " for " $t=0$ " or " $t=\infty$ ", " $i$ " for the tubes (if necessary) and "a" for the shell of the exchanger. Bulk temperatures $\mathrm{T}$ will be considered.

The following quantities will be defined:

- overall heat capacity $\mathrm{C}$ and averaged temperature $\mathfrak{I}$ :

$$
\left\{\begin{array}{l}
C=C_{h}+C_{c}+C_{i}+C_{a} \\
\mathfrak{I}=\frac{C_{h} \mathfrak{I}_{h}+C_{c} \mathfrak{I}_{c}+C_{i} \mathfrak{I}_{i}+C_{a} \mathfrak{I}_{a}}{C}
\end{array}\right.
$$

- $\quad$ heat capacity flow rates $\left(\mathrm{q}_{\mathrm{m}}=\right.$ mass flow rate):

$q_{t c}=q_{m c} C_{c} ; q_{t h}=q_{m h} C_{h}$

By the mean of an energy balance, and using assumptions 6.1, it can be shown that the time constant is expressed by:

$$
\tau=\frac{C\left(\mathfrak{I}_{0}-\mathfrak{I}_{\infty}\right)}{q_{t h \infty}\left(T_{h s 0}-T_{h s \infty}\right)+q_{t c \infty}\left(T_{c s 0}-T_{c s \infty}\right)}
$$

We can observe that the time constant depends on the initial and final exit bulk temperatures, which can be expressed as functions of the initial and final entrance temperatures and of initial and final flow rates, i.e. consequently as functions of NTU, unbalance factor $\mathrm{R}=\mathrm{q}_{\mathrm{t} \min } / \mathrm{q}_{\mathrm{t} \max }$ and effectiveness $\mathrm{E}$.

\section{Results}

An analytical formulation of the time constant $\tau$, though it is approximate, allows easy and interesting parametric studies.

First it can be shown that the flow arrangement (parallel or counter-flow), which has a strong influence on the thermal performances of the exchanger, has a very little effect on the time constant [52]. Another elementary property is that $\tau$ appears as a linear function of the exchanger length $[52,54]$.

In the case of shell-and-tube heat exchangers, fig. 6.2. shows on a special case the influence of a flow rate step (expressed as a heat capacity flow rate): as the heat capacity flow rate of the hot fluid increases $\left(\Delta q_{h}>0\right.$, upper curve $), \tau$ increases almost exponentially; in the case of a decreasing flow rate $\left(\Delta q_{h}<0\right.$, lower curve), $\tau$ decreases slightly and linearly.

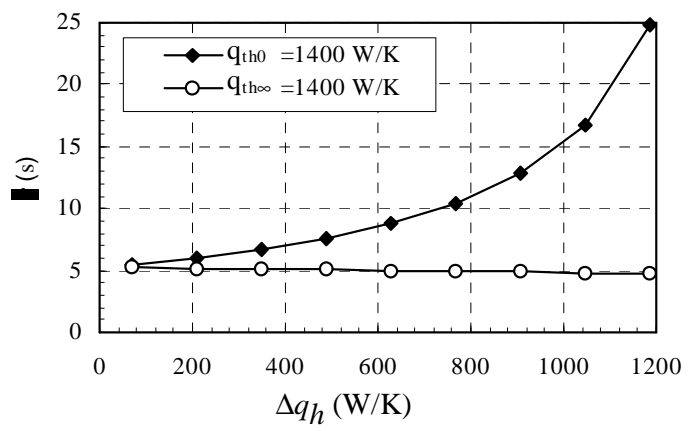

Figure 6.2. Flow rate step on the hot fluid: influence on the time constant ( heat capacity flow rate of the cold fluid: $q_{t c}=210 \mathrm{~W} / \mathrm{K}$ ).

Moreover, when only one temperature step is applied, the time constant is independent of its value. In such circumstance, $\tau$ decreases as the hot (or cold) flow rate increases (fig. 6.3). A similar evolution is observed when a negative flow rate is applied (fig. 6.4: $\tau$ is plotted as a function of the final value qth $\infty$ of the heat capacity flow rate, which initial value is $1400 \mathrm{~W} / \mathrm{K}$ ). At last, it can be seen that the time constant is smaller with flow rate variations than with temperature variations.

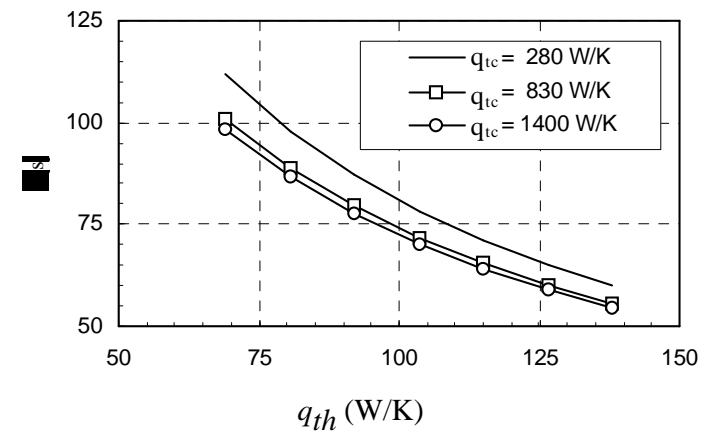

Figure 6.3. Influence of the flow rates on the time constant (temperature step on the hot or on the cold fluid).

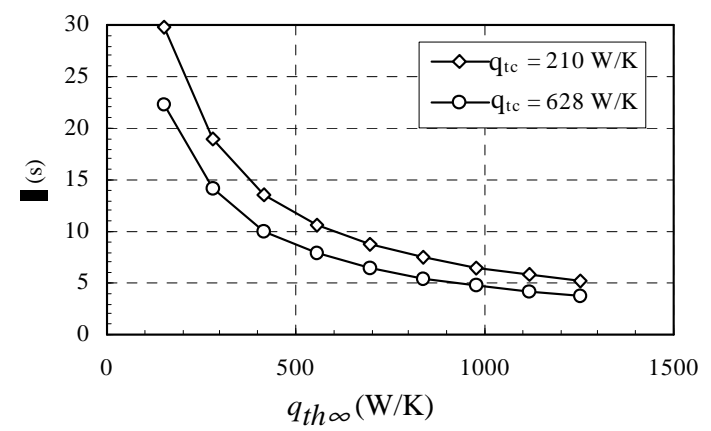

Figure 6.4. Influence of the flow rate on the time constant (step on the hot fluid, $\left.q_{\text {th } 0}=1400 \mathrm{~W} / \mathrm{K}\right)$.

\section{J. of the Braz. Soc. of Mech. Sci. \& Eng.


Fig. 6.5 shows another case where the cold fluid is submitted to a flow rate step. As we observe, it is difficult to give a simple law for the variation of the time constant as a function of the initial flow rate of the cold fluid, but we can realise that there is a big variation of the time constant in the transition state from laminar to turbulent flow. Moreover, this variation seems to be more sensitive as the final flow rate is in the transition state. This shows the simultaneous influence of the different parameters in such situations and the difficulty to separate one parameter from the others [54].

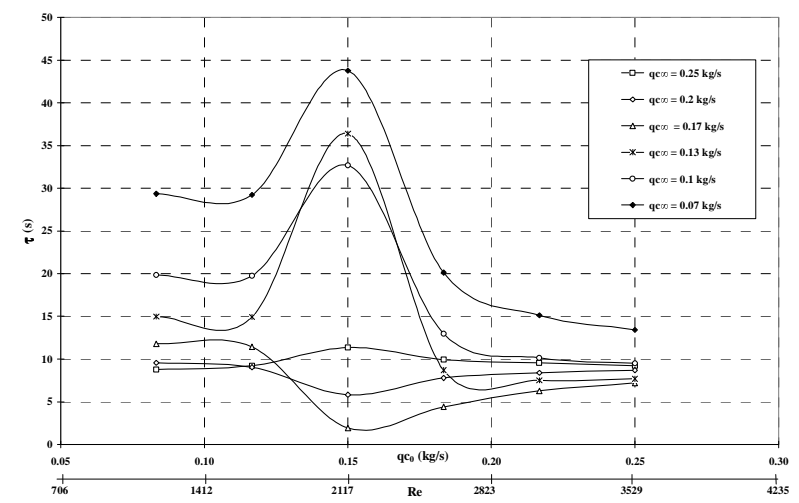

Figure 6.5. Bitubular heat exchanger: influence of the initial flow rate of the cold fluid in the annular tube, for different values of the final flow rate $\left(q_{h \infty}=0.12 \mathrm{~kg} / \mathrm{s}=\mathrm{cst}\right)$.

\section{Time Lag}

An accurate prediction of outlet temperatures under variable conditions needs the knowing of both time constant $\tau$ and time lag $t_{\mathrm{r}}$. Unfortunately, evaluations of $t_{\mathrm{r}}$ cannot result from a theoretical approach, and need experimenatal procedures.

Some trends have been investigated on a $2 \mathrm{~m}$ length, double pipe water-water heat exchanger [55], in which the hot water flows inside the inner duct, and is submitted to flow rate steps. Correlations have been built to express the two time lags $t_{\mathrm{rc}}$ (cold fluid outlet) and $\mathrm{t}_{\mathrm{rh}}$ (hot fluid outlet). Some examples are plotted on fig. 6.6 to 6.9 as functions of the final flow rate $\mathrm{q}_{\mathrm{c} \infty}$, and show that $\mathrm{q}_{\mathrm{co}}$ has a stronger influence on $t_{r c}$ than on $t_{r h}$, whatever the flow arrangement.

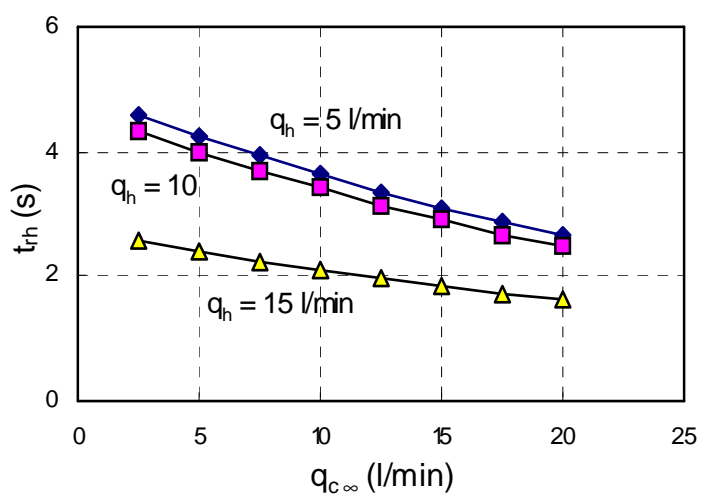

Figure 6.6. Time lag of the hot fluid case of parallel flow with a flow rate step on the cold fluid $\left(\Delta q_{c}=2.5 \mathrm{l} / \mathrm{min}\right)$.

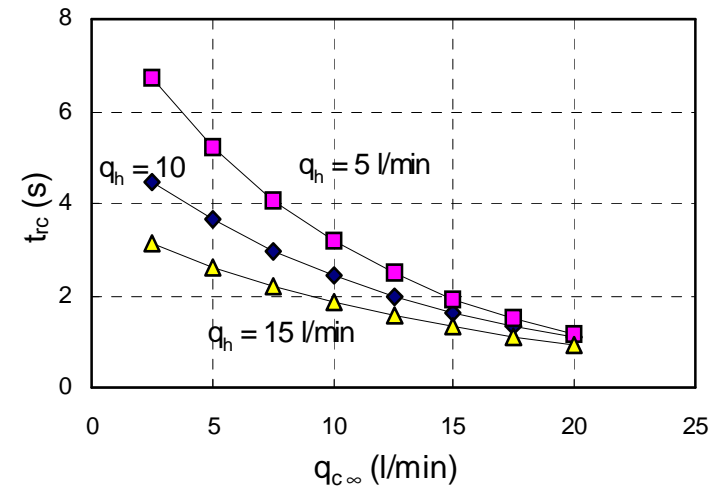

Figure 6.7. Time lag of the cold fluid case of parallel flow with a flow rate step on the cold fluid $\left(\Delta q_{c}=2.5 \mathrm{l} / \mathrm{min}\right)$

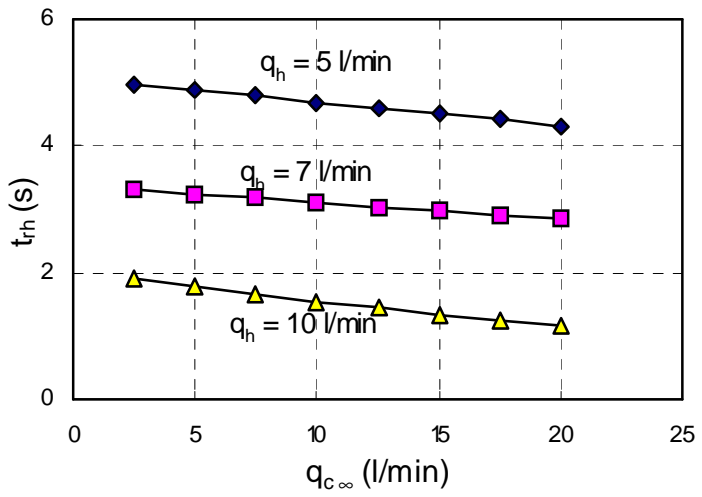

Figure 6.8. Time lag of the hot fluid case of counter flow with a flow rate step on the cold fluid. $\left(\Delta \mathrm{q}_{\mathrm{c}}=2.5 \mathrm{l} / \mathrm{min}\right.$

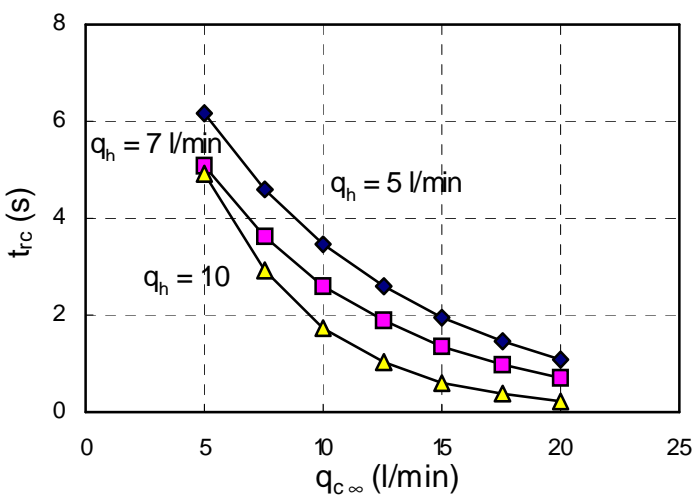

Figure 6.9. Time lag of the cold fluid case of counter flow with a flow rate step on the cold fluid. $\left(\Delta q_{c}=2.5 \mathrm{l} / \mathrm{min}\right.$

Take also notice that the two-parameter model has been successfully applied to water plane solar collectors [56].

\section{Effectiveness Under Variable Conditions [57 To 60]}

As a complementary investigation to the previous studies, a new method has been proposed to determine the thermal effectiveness of heat exchangers when one of the fluids is submitted to any kind of flow rate variations. When the operating conditions are varying with time, the validity of the classical definition vanishes, so the method leads to the concept of an average effectiveness in unsteady state. This average effectiveness can be easily determined by measuring continuously during a time $t_{\mathrm{e}}$ the exit temperatures and flow rates. 
The method is applicable under the condition $t_{e}>10 \tau$, and fig. 6.10 shows that the instantaneous effectiveness converges quickly toward its averaged value [58]
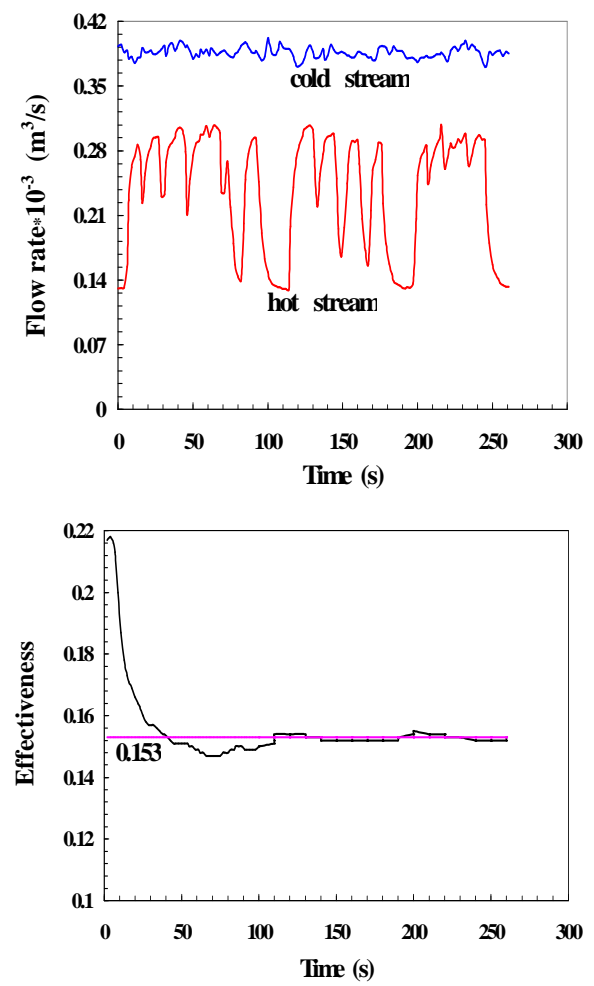

Figure 6.10. Temporal evolution of the effectiveness on the hot fluid side.

\section{Numerical Model [64]}

In order to get a better understanding of transient states in heat exchangers, local investigations are necessary. Analytical and numerical methods have been employed in the case of a single duct $[61,62,63]$. They were completed by a numerical study (using a finite difference scheme) of a parallel plate heat exchanger, when the two fluids are submitted to temperature steps at the entrance [64]: the two channels (thermally insulated on their external sides) are separated by a thin plate with on thermal resistance, and their thickness are $2 \mathrm{~cm}$. Some results are presented on fig. 6.11 to 6.17 for water-water or air-water arrangements, and show complex evolutions of the temperatures in the system.

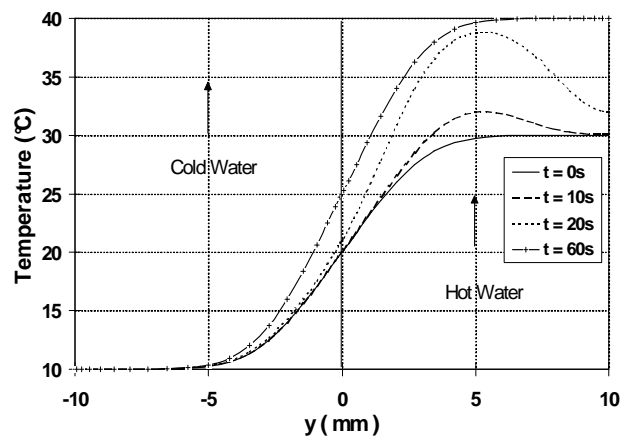

Figure 6.11. Temperature profiles at $\mathrm{x}=0.5 \mathrm{~m}$ for $\Delta \mathrm{T}_{\mathrm{he}}=+10$ et $\Delta \mathrm{T}_{\mathrm{ce}}=\mathrm{O}^{\circ} \mathrm{C}$ (water-water).

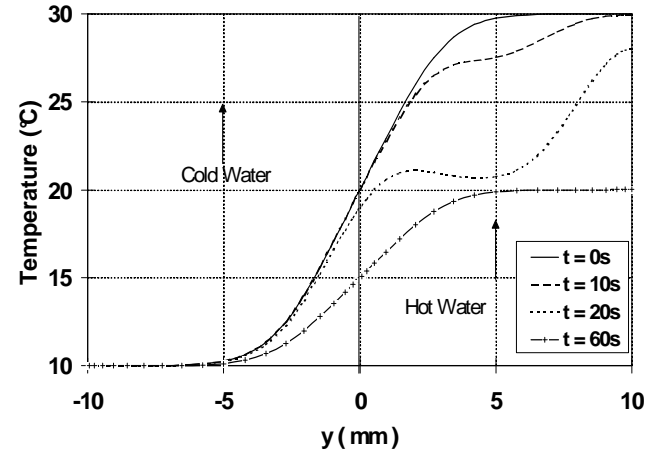

Figure 6.12. Temperature profiles at $\mathrm{x}=0.5 \mathrm{~m}$ for $\Delta \mathrm{T}_{\mathrm{he}}=-10$ et $\Delta \mathrm{T}_{\mathrm{ce}}=\mathrm{O}^{\circ} \mathrm{C}$ (water-water).

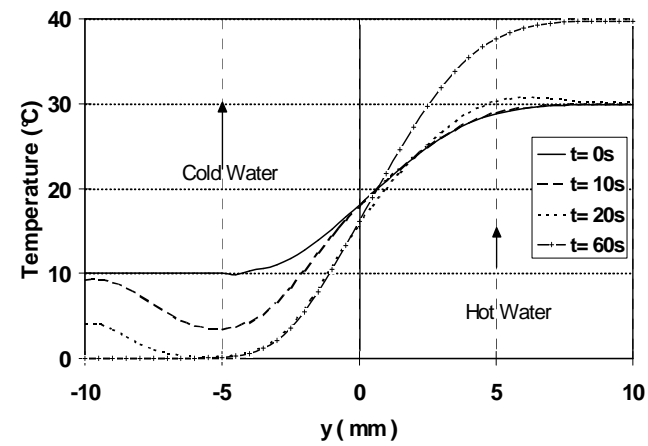

Figure 6.13. Temperature profiles at $\mathrm{x}=0.5 \mathrm{~m}$ for $\Delta \mathrm{T}_{\mathrm{he}}=+10$ and $\Delta \mathrm{T}_{\mathrm{ce}}=-10^{\circ} \mathrm{C}$ (water-water).

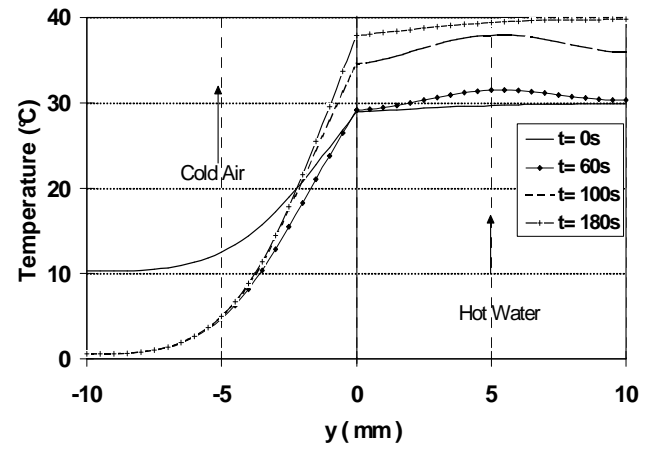

Figure 6.14. Temperature profiles at $\mathrm{x}=0.5 \mathrm{~m}$ for $\Delta \mathrm{T}_{\mathrm{he}}=+10$ et $\Delta \mathrm{T}_{\mathrm{ce}}=-10^{\circ} \mathrm{C}$ (air-water).

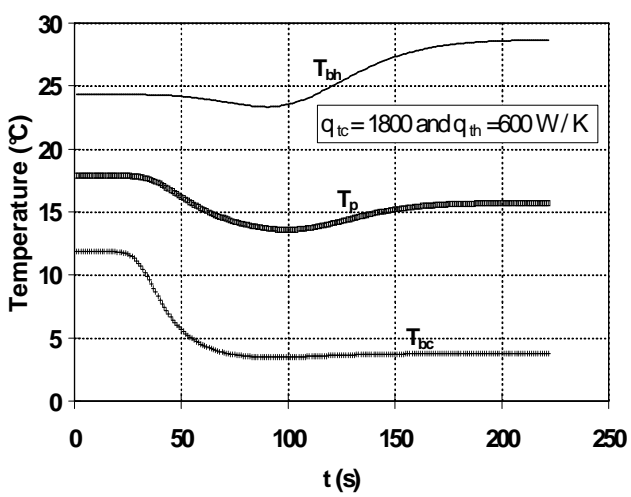

Figure 6.15. Exit bulk and plate temperatures $\Delta \mathrm{The}=+10$ and $\Delta \mathrm{Tce}=-10^{\circ} \mathrm{C}$ (water-water). 


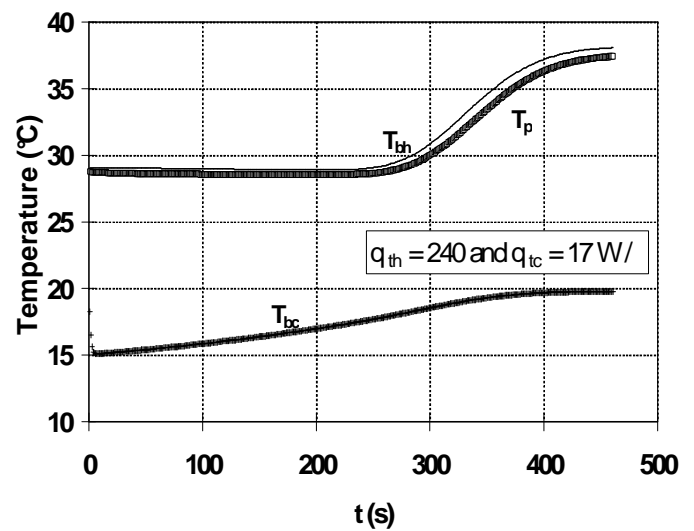

Figure 6.16. Exit bulk and plate temperatures $\Delta T_{h e}=+10$ et $\Delta T_{c e}=-10^{\circ} \mathrm{C}$ (water-air).

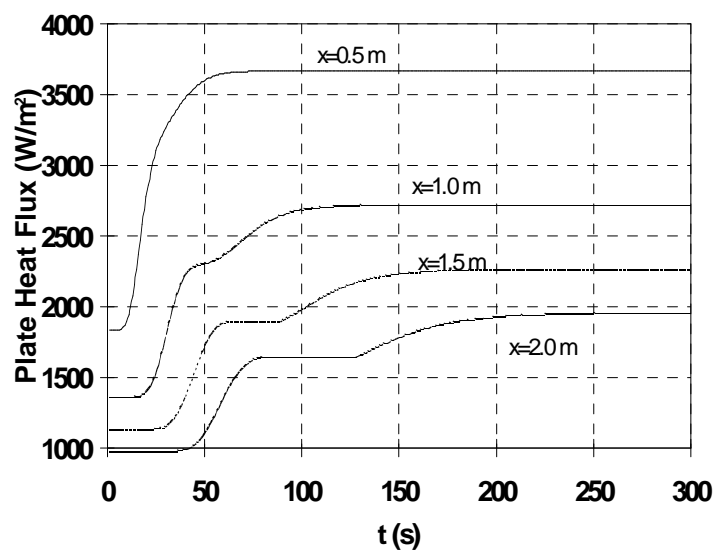

Figure 6.17. Evolution of the plate heat flux at different locations $\Delta T_{h e}=$ $+10, \Delta \mathrm{T}_{\mathrm{ce}}=-10^{\circ} \mathrm{C}$ (water-water).

\section{References} (1995)

S. Kakaç, Y. Yener - Convective heat transfer. CRC Press, Miami

T. Cebeci - Physical and computational aspects of convective heat transfer. Springer-Verlag, New-York (1984)

Transient convective heat transfer. J. Padet, F. Arinç Ed., Begell House, New-York (1996)

Transient convective heat and mass transfer in single and two-phase flows. J. Padet, F. Arinç Ed., Begell House, New-York (2003)

M. Rebay, J. Padet, E. Mladin - Unsteady convective heat transfer in similar flows with pressure gradient. 3rd European Thermal Science Conf. 2000, Proc. p.259-264, Heidelberg, Germany (2000)

M. Rebay, M. Lachi, J. Padet - Extension de la méthode des solutions affines à un problème de couche limite laminaire en régime transitoire. Congrès Français de Thermique SFT 97, Toulouse, Proc. p.489-494, Elsevier (1997)

M. Rebay, J. Padet - Transient laminar forced convection from a wedge flow, Int. Comm. Heat Mass Transfer, vol. 31, N4, p.537-548 (2004)

G. Polidori, J. Padet - Heating and partial cooling problems in unsteady forced convection. European Phys. J. Appl. Phys. 4, p.235-238 (1998)

M. Rebay, G. Polidori, J. Padet - Complément d'analyse sur les écoulements de type couche limite en convection laminaire forcée. Congrès Français de Thermique SFT 98, Proc. p.27-32, Elsevier (1998)

G. Polidori, M. Rebay, J. Padet - Retour sur les résultats de la théorie de la convection forcée laminaire établie en écoulement de couche limite externe. Int. J. Thermal Sciences, 38, p.398-409 (1999)

M. Rebay, J. Padet - Laminar boundary - layer flow over a semi infinite plate impulsively heated or cooled. Eur. Phys. J. Applied Physics, 7, p.263-269 (1999)
M. Rebay, M. Lachi, J. Padet - From the dimensionless results to the physical ones in transient heat transfer convection, Transient convective heat and mass transfer, J. Padet, F. Arinc Ed., Begell House, p.143-152 (2003)

M. Lachi, M. Rebay, E. Mladin, J. Padet - Integral approach of the transient convective heat transfer over a plate exposed to a temporal variation of heat flux, Transient convective heat and mass transfer, J. Padet, F. Arinc Ed., Begell House, p.501-510 (2003)

G.Polidori, M.Lachi, J.Padet - Comportement d'une couche limite thermique en écoulement cisaillé avec chauffage spatio - périodique à la paroi. C.R. Acad. Sci. Paris, t.326, Série II b, pp.429-432 (1998)

G. Polidori, J. Padet - Transient laminar forced convection with arbitrary variation in the wall heat flux. Heat and Mass Transfer - Wärme und Stoffübertragung, 38, p.301-307 (2002)

M. Lachi, G. Polidori, M. Rebay, J. Padet - Convection forcée instationnaire sur une plaque soumise à une perturbation de flux périodique. 14ème Congrès Français de Mécanique, réf. 204, Toulouse (septembre 1999)

J. Padet, Th. de Lorenzo - Similitude problems in convective heat and mass transfer; rational use of similitude criteria. Int. Symp. on Transport Phenomena ISTP-12, Istanbul, published in Recent advances in Transport Phenomena, p.287-296, Elsevier (2000)

G.Polidori, M.Lachi, J.Padet - Unsteady convective heat transfer on a semi-infinite flat surface impulsively heated. Int. Communications in Heat and Mass Transfer, 25, $\mathrm{N}^{\circ}$ 1, pp. 33-42 (1998)

M. Rebay, J. Padet - Transient laminar forced convection from a wedge flow, Int. Comm. Heat Mass Transfer, vol. 31, N4, p.537-548 (2004)

M. Lachi, M. Rebay, E. Mladin, J. Padet - Alternative models for transient convection heat transfer in external flows over a plate exposed to a variable heat flux. Int. J. Thermal Sciences, 43, Nº, p.809-816 (2004)

E. Mladin, A. Trif, M. Rebay, J. Padet - Couplage convectionconduction en régime transitoire entre un écoulement et une plaque plane soumise à un échelon de flux thermique. Congrès COFRETH' 02, Actes p.318-325, Bucarest, Romania (2002)

E. Mladin, M. Lachi, J. Padet - Transfert de chaleur couplé conduction - convection en régime instationnaire, induit par une température imposée sur une plaque d'épaisseur finie. Congrès Français de Thermique SFT 2001, Actes p.87-92, Elsevier (2001)

M. Lachi, M. Rebay, E. Mladin, J. Padet - Etude de la convection forcée transitoire sur une plaque plane avec la méthode intégrale, Journée Société Française de Thermique "Régimes transitoires en convection", Paris (décembre 2003)

E. Mladin, J. Padet - Unsteady planar stagnation flow on a heated plate. Int. J. of Thermal Sciences, 40, $\mathrm{N}^{\circ}$ 7, p.638-648 (2001)

J. Padet, Th. de Lorenzo - Similitude criteria for free convective heat and mass transfer. Int. J. of Energy Research, 26, p.365-381 (2002)

Th. de Lorenzo, J. Padet - Parametric study of transient free convection heat transfer. Int. J. of Heat and Mass Transfer, 45, $\mathrm{N}^{\circ} 12$, p.2629-2632 (2002)

Th. de Lorenzo, J. Padet - Investigation of convective heat transfer optimization using differential method. IVth. Int. Thermal Energy Congress ITEC 2001, Proc. p.287-292, Cesme, Turkey (2001)

Th. de Lorenzo - Convection naturelle transitoire le long d'une surface verticale soumise à une densité de flux périodique. C.R. Acad. Sciences Paris, tome 330, fascicule 3, p.181-184 (2002)

J. Padet - Principes des transferts convectifs. 280 p., Ed. Polytechnica Economica, Paris (1997)

Th. de Lorenzo, G. Polidori, E. Mladin - Discussion sur la théorie d'Eckert en convection naturelle laminaire sur une surface verticale. 14ème Congrès Français de Mécanique, réf. 60, Toulouse (septembre 1999)

G. Polidori, E. Mladin, Th de Lorenzo - Extension de la méthode de Karman-Pohlhausen aux régimes transitoires de convection libre pour Pr>0,6. C.R. Acad. Sciences Paris, t.328, p.763-766 (2000)

G. Polidori, Th. de Lorenzo, J-F. Henry - Généralisation de la méthode intégrale aux écoulements transitoires plans de convection naturelle. Congrès Français de Thermique SFT 2000, Actes p.169-174, Elsevier (2000)

G. Polidori, C. Popa, T.H. Mai - Transient flow rate behaviour in an external natural convection boundary layer, Mechanics Research Comm., 30 (2003) p.615-621

J. Padet, Th. de Lorenzo - Similitude criteria for free convective heat and mass transfer. Int. J. of Energy Research, 26, p.365-381 (2002)

G. Polidori, X. Gassmann, J. Padet - Unsteady flow patterns in the vicinity of a heated wall mounted transverse ribs. Annals of the New-York Acad. of Sciences, 972, p.193-199 (2002)

G. Polidori, J. Padet - Flow visualization and free convection heat transfer at the junction of short cylinders mounted on a heated wall, J. of Flow Visualization and Image Processing, vol. 10, p.13-25 (2003) 
G. Polidori, J. Padet - Transient free convection flow on a vertical surface with an array of large-scale roughness elements, Experimental Thermal and Fluid Science, 27, p.251-260 (2003)

T.H. Mai, N. El Wakil, J. Padet - Transient mixed convection in a vertical pipe flow : temporal evolution following an inlet temperature step. Int. Communications in Heat and Mass Transfer, 21, $\mathrm{N}^{\circ} 5$, p.755-764 (1994)

T.H. Mai, N. El Wakil, J. Padet - Numerical study of mixed convection in vertical pipe flows with inlet flow rate step ; application to water radiators. Transient convective heat transfer, p.271-280, F. Arinç, J. Padet Red., Begell House, New York (1997)

V. Pavel, N.C. Chereches, T.H. Mai - Convection mixte sur une plaque plane verticale en régime variable: modèle thermo-hydraulique, Bulletin de l'Institut Polytechnique de Iasi, Roumanie, tome XLVII, Fasc. 1-2, p.59-69 (2001)

T.H. Mai, C.V. Popa - Numerical study of transient mixed convection in vertical pipe flows. Advances in Fluid Mechanics IV, p.75-84, M. Rahman, R. Verhoeven \& C. Brebbia Ed., WIT Press (2002)

T.H. Mai, N. El Wakil, J. Padet - Transfert de chaleur dans un tube vertical avec écoulement de convection mixte à débit variable. Int. J. Thermal Sciences (ex Revue Générale de Thermique), 38, p. 277-283 (1999)

T.H. Mai, J. Padet - Comportement thermohydraulique d'un écoulement dans un tube vertical en convection mixte instationnaire. 14ème Congrès Français de Mécanique, réf. 5008, Toulouse (septembre 1999)

C.V. Popa, T.H. Mai - Numerical analysis of laminar mixed convection flow instabilities in a vertical pipe, Transient convective heat and mass transfer, p.281-290, J.Padet, F. Arinc Ed.,Begell House, New-York, (2003)

C.V. Popa, T.H. Mai - Etude de stabilité de l'écoulement en convection mixte transitoire, Congrès COFRET'04, Nancy, Actes p.293-299 (2004)

T.H. Mai, R. Zebiri, Th. de Lorenzo - Convection mixte en régime transitoire de couche limite sur une plaque verticale. C. R. Acad. Sci. Paris, t.329, Série IIb, p.627-631 (2001)

D. Crowther, J. Padet - Measurement of the local convection coefficient by pulsed photothermal radiometry. Int. J. of Heat and Mass Transfer, 34, $\mathrm{N}^{\circ} 12$, p.3075-3081 (1991)

D. Crowther, J. Padet - Application de la méthode photothermique impulsionnelle à la détection simultanée des coefficients d'échange des deux côtés d'une paroi thermiquement mince. C.R. Acad. Sciences Paris, 314, série II, p.33-36 (1992)

M. Rebay, M. Lachi, J. Padet, "Mesure de coefficients d'échange de chaleur entre un mur d'épaisseur finie et un écoulement d'air". Actes du IVe Colloque Interuniversitaire Franco - Québécois "Thermique des Systèmes à température modérée”, Montréal, Canada, p.89-94 (1999)
M. Rebay, M. Lachi, J. Padet - Mesure de coefficients de convection par méthode impulsionnelle. Influence de la perturbation de la couche limite. Int. J. of Thermal Sciences, $\mathrm{N}^{\circ}$ 11, vol. 41, p.1161-1175 (2002)

P. Pierson - Etude théorique et expérimentale de systèmes thermiques en régime instationnaire : échangeurs, capteurs solaires, installations solaires actives. Thèse de Doctorat d'Etat, Université de Reims, France (1986)

N. El Wakil, M. Lachi, M. Guellal - Transient behaviour of shell-andtube heat exchangers. Eurotherm Seminar 46 «Heat transfer in single phase flows 4 », Pisa, Italia, Proc. p.141-147 (1995)

M. Hadidi, M. Guellal, M. Lachi, J. Padet - Loi de réponse d'un échangeur thermique soumis à des échelons de température aux deux entrées. Int. Communications in Heat and Mass Transfer, 22, $\mathrm{N}^{\circ} 1$, p.145-154 (1995)

M. Lachi, N. El Wakil, J. Padet - The time constant of double pipe and one pass shell-and-tube heat exchangers in the case of varying fluid flow rates. Int. J. Heat and Mass Transfer, 40, N99, p.2067-2079 (1997)

N. El Wakil, J. Padet - Transient behaviour of a double pipe heat exchanger submitted to a flow rate step at the entrance. Congrès International ECOS'98, Actes p.933-939, Nancy, France (1998)

P. Pierson, J. Padet - Time constant of solar collectors. Solar Energy, 44, p.109-115 (1990)

T.H. Mai, N. Chitou, J. Padet - Method for the heat exchanger effectiveness calculation under variable dynamic conditions. Int. Communications in Heat and Mass Transfer, 26, N5, p.739-748 (1999)

T.H. Mai, N. Chitou, J. Padet - Heat exchanger effectiveness in unsteady state. Eur. Phys. J. Applied Physics, 8, p.71-75 (1999)

N. Chitou, T-H. Mai, J. Padet - Etude de l'efficacité d'un échangeur en régime variable. Entropie, 220/221, p. 86-91 (1999)

P. Pierson, L. Pinçon, J. Padet - Définition d'une efficacité moyenne pour un échangeur fonctionnant en régime thermique variable. Int. Communications Heat Mass Transfer, 17, N5, p.567-566 (1990)

R.M. Cotta, M.N. Ozisik - Transient heat transfer in channel flow with step change in inlet temperature. Numerical Heat Transfer, 9, p.619 (1986)

R.M. Cotta, M.N. Ozisik - Laminar forced convection inside ducts with periodic variation of inlet temperature. Int. J. Heat Mass Transfer, 29, p.1495 (1987)

J. Brown, S. Kakaç - Transient laminar forced convection heat transfer with periodic variation of inlet temperature in circular ducts. Tenth Int. Heat Transfer Conf., Brighton, U.K., Proc. vol.4, p.199-204 (1994)

N. El Wakil, M. Rebay, J. Padet - Numerical study of transient forced convection in parallel-plate heat exchanger. Transient convective heat transfer, p.305-314, F. Arinç, J. Padet Ed., Begell House, New York (1997) 
J. Padet 